Original Research Paper

\title{
Isolation and Characterization of Chemical Constituents, Cytotoxicity, Antibacterial and Antioxidant Activity of the Compounds from Leptadenia hastata Roots Extract By
}

\author{
${ }^{1,2}$ Isaac John Umaru and ${ }^{3}$ Hauwa A. Umaru \\ ${ }^{1}$ Faculty of Resource Science and Technology, Universiti of Malaysia Sarawak, Kota Samarahan, Malaysia \\ ${ }^{2}$ Department of Biochemistry Federal University Wukari, Taraba State, Nigeria \\ ${ }^{3}$ Department of Biochemistry, Modibo Adama University of Technology Yola Adamawa State, Nigeria
}

\author{
Article history \\ Received: 10-08-2019 \\ Revised: 04-10-2019 \\ Accepted: 20-12-2019 \\ Corresponding Author: \\ Isaac John Umaru \\ Faculty of Resource Science \\ and Technology, Universiti of \\ Malaysia Sarawak, Kota \\ Samarahan, Malaysia and \\ Department of Biochemistry \\ Federal University Wukari, \\ Taraba State, Nigeria \\ Email: isaac.j62@yahoo.com
}

\begin{abstract}
The aim of this work was to extract, isolate and characterise the chemical constituent from Leptadenia hastata roots. Fresh roots were washed and dried and was subjected to sequential maceration in polar and non-polar solvents. And introduced into rotary evaporator to concentrate the extract. Isolated compound was subjected to Thin Layer Chromatography and spectral analysis such as column and UV-Visible spectroscopy were used in the detection of the spots, Gas ChromatographyMass Spectrophotometric (GC-MS). Characterization was done using Nuclear Magnetic Resonance and Furrier Transform-Infra Ray (FT-IR) as shown the flow chart. Disc diffusion method was applied for the antibacterial test. Brine shrimp for cytotoxicity, DPPH for Antioxidant. The isolated compound were Methyl biphenyl-4-Carboxylate (1) and Methyl salicylate (2). Higher cytotoxicity was observed in the isolated pure compound with $\mathrm{LC}_{50}$ of $8.770 \mu \mathrm{g} / \mathrm{mL}$ and $23.982 \mu \mathrm{g} / \mathrm{mL}$. The Antioxidant $\mathrm{IC}_{50}$ activity was observed to be $77.79 \mu \mathrm{g} / \mathrm{mL}$ and $61.96 \mu \mathrm{g} / \mathrm{mL}$ and the compounds was observed to have significant activity on Escherichia coli, Klebsiella pneumonia and Salmonella typhi. From this studies it was concluded that the isolated compounds from the root extract of Leptadenia hastata was confirmed as Methyl biphenyl-4-Carboxylate (1) and Methyl salicylate (2) and a very strong Antioxidant, cytotoxicity, was established. Antibacterial potential was observed against Escherichia coli, Klebsiella pneumonia and Salmonella typhi. Thus could be used as an agent for anticancer, antibacterial and as a good source of antioxidant. This compounds though common was isolated and characterized for the first time from the roots extracts Leptadenia hastata.
\end{abstract}

Keywords: Isolation, Characterization, Chemical Constituents, Cytotoxicity, Antibacterial, Antioxidant, Roots, Leptadenia hastata

\section{Introduction}

Leptadenia hastata is edible non-domesticated vegetable and it is collected in wild throughout Africa. The plant is a voluble herb with creeping latex stems, glabescent leaves, glomerulus and racemus flowers as well as follicle fruits. It is typically grown in tropical dry lands in sandy soil. Wild foods like Leptadenia hastata provide food security during seasonal changes and are used medicinally in many areas (Thomas, 2012).

The plant is able to continue growing in harsh, dry conditions when other plants are dying, it is commonly used among Michika communities in the north eastern part of Nigeria as a spice and as sauces. Traditional medical practitioner uses the plant as a remedy for anthypertension, catarrh and skin diseases. The roots are used to treat scabies and locally used for sexual potency (Umaru et al., 2018).

Plant contain many active compounds such as alkaloids, steroids, tannins, glycosides, volatile oils, fixed oils, resins, phenols flavonoids etc., which are deposited in their specific parts such as leaves, flowers, bark, seeds, fruits and the root.

The objective of the study was to isolate chemical constituents from the roots extract and evaluate the cytotoxicity, antibacterial and antioxidant potential of the 
compounds (Mohanty et al., 2017). This study draws attention to the need for further studies of the active secondary metabolites identified as an agent for the treatment of many diseases and to understand their mode of action in controlling various dreadful diseases.

\section{Materials and Methods}

\section{Materials}

Chemicals and solvent used in this study were of analytical standard and are obtained from Sigma Chemical Co., St Louis, USA. Standard were obtained from Oxoid Ltd, Wade Road, Basingstoke, Hants, RG24 8PW, UK. Bacterial were obtained from virology Laboratory Universiti Malaysia Sarawak.

\section{Sample Collection}

The roots of Leptadenia hastata were uprooted from uncultivated land in Michika Local Government of Adamawa state north-eastern part of Nigeria as shown in Figure 1. The sample was identified by Hauwa A. Umaru of Modibbo Adama University of Technology yola and authenticated by a botanist in the Department of Agriculture. voucher numbers are as follow; LH1971/DAFST/2015-08/001. The roots were carefully washed with distilled water not to lose any part of the roots. It was air dried, blended and grounded into powder using pestle and mortar in the laboratory. The finely ground powdered samples were packed into clean, dry sample containers and were labelled appropriately and kept for further use.

\section{Preparation of Leptadenia hasstata Roots Extract}

Extraction was carried out by the conventional solvent extraction method described by Fasihuddin et al. (2010) with slight modification. This was achieved by soaking the ground plant material in solvents in the order of increasing polarity. A total of $2 \mathrm{~kg}$ of the dried and ground powdered sample was extracted using cold soaking method with hexane. The sample were soaked in the hexane with the ratio of 1:3 (sample: hexane) in a 5 liters Erlenmeyer flasks at room temperature for 5-7 days. The resulting hexane solution was then filtered using Whatman filter paper No 4 and the residue was then re-extracted with fresh hexane for another $72 \mathrm{~h}$ and filtered. Both extracts were combined and evaporated to dryness with a rotary evaporator (Heidolph Laborota 4000 efficient) under reduced pressure below $50^{\circ} \mathrm{C}$ to obtain the hexane crude extract. The residue was re-extracted using similar procedure with dichloromethane, followed by chloroform, ethyl acetate and methanol to obtain respective crude extracts. The dry weight and percentage yield of each crude extract were determined.

\section{Column Chromatography}

The basic principle of column chromatography is to separate a mixture of metabolites based on their molecular weight and polarity. A glass column of size 40/34 (large) was used for chromatography and the sorbent used was silica gel 60 (Merck 70-230 Mesh ASTM $0.0630 .200 \mathrm{~mm}$ ). Silica gel slurry was prepared by dissolving silica gel (150 g) with suitable solvent, usually hexane. The column was prepared by pouring a slurry mixture of silica gel and solvent, into a glass column and allow it to settle down (Firdous et al., 2013). The packed column was left overnight before 4-10 $\mathrm{g}$ of sample was introduced onto the top of the packed column via dry-packing method. The column was eluted with suitable solvent systems with increasing polarity Fasihuddin et al. (2010). The column's valve was then opened and about 10-30 mL fraction of the solvent coming out from the column was collected in test tubes (Patra et al., 2012). The procedure was repeated by using different solvent systems, based on increasing polarity. Samples from the column fractions were examined by using TLC plates in few suitable solvent systems to obtain the retention factor $\left(R_{f}\right)$ of any components that appeared as spots. Fractions with similar $R_{f}$ values were combined (Patra et al., 2012). Fractions which contain more than one component were further isolated and purified by using smaller glass column of sizes 24/29 (medium) and $14 / 23$ (small) with suitable solvent systems.

Fraction with single component (one spot) that appeared in TLC plate was treated as possible pure secondary metabolite. The combined fractions which contained the same single component was then allowed to air-dried or evaporated to dryness to obtain a pure secondary metabolite.

\section{Thin Layer Chromatography (TLC)}

The eluents collected from column chromatography, were subjected to Thin Layer Chromatography (TLC) analysis. TLC was carried out using the method described by Fasihuddin et al. (2010). A glass capillary tube was used to apply samples on the TLC plates (size $6.6 \times 20 \mathrm{~cm}, 5 \times 20 \mathrm{~cm}$ ) repeatedly with a spot of about $0.3 \mathrm{~mm}$ in diameter. The TLC plate was then placed in a rectangular glass developing chamber with its lower marked edge ( $1 \mathrm{~cm}$ from the base) dipped into a developing solvent below the mark where the samples were spotted. The plates were allowed to develop to the level of upper mark ( $4 \mathrm{~cm}$ from the base) and then removed and dried. The TLC plates were then viewed directly for colored compounds, it was also viewed under UV box for UV fluorescent compound and stained with vanillin for compound that are neither visible nor UV fluorescence. Fractions containing similar characteristics were combined and dried. 


\section{Chemical Structure Elucidation}

\section{Gas Chromatography-Mass Spectrometry (GC-MS)}

Gas Chromatography (GC) analysis of fractions that were obtained from TLC as single spot was performed using a Shimadzu GC-Mass Spectrometry model QP2010 plus, equipped with a BPX-5 column (5\% phenyl polysylphenlenesiloxane) of $30 \mathrm{~m}$ in length, film thickness of $0.25 \mu \mathrm{m}$ and internal diameter of $0.25 \mathrm{~mm}$. The operating method was based on the method described by Kalaiselvan et al. (2012). Ionization energy of $70 \mathrm{eV}$ was used in the electron ionization energy system of the GC-MS for detection and carrier gas, helium $(99.999 \%)$ at a constant flow rate of $1 \mathrm{~mL}$ per min was used. Exactly $1 \mu \mathrm{L}$ of purified sample was injected into the GC-MS using a syringe and sample was analyzed using split mode with ration of 25:1. Injection temperature was set at $260^{\circ} \mathrm{C}$ and the oven temperature was programmed from $60^{\circ} \mathrm{C}$ with an increase of $10^{\circ} \mathrm{C}$ per min, isothermal for $5 \mathrm{~min}$, to $280^{\circ} \mathrm{C}$, ending with 10 min isothermal at $280^{\circ} \mathrm{C}$ at $70 \mathrm{eV}$. Mass spectra was taken at a scan interval of $0.5 \mathrm{sec}$ and fragments from 45 to $450 \mathrm{Da}$. By matching its average peak area to the total areas, the relative percentage quantity of each component was acquired. Compound identification was obtained by matching the retention times of the compounds and the mass spectral obtained from the library data of the corresponding compound.

\section{Fourier Transform Infra-Red Spectrometry (FT-IR)}

Fourier Transform Infra-Red (FT-IR) was performed using FTIR spectroscopy (Thermos Scientific, Nicolet iS10 SMART iTR) to detect the chemical bonds (functional groups) of the compounds. The operating system was based on the method described by Shalini and Sampathkumar (2012). The liquid samples were introduced into the machine and scan range was set from 400 to $4000 \mathrm{~cm}^{-1}$ with a resolution of $4 \mathrm{~cm}^{-1}$. Characteristic of the chemical bonds was read by spectrum produced through transmittance of wavelength of light. The chemical bond in a molecule were detected by interpreting the infra-red transmittance spectrum and the functional groups of the compounds were identified based on the Table of Characteristic IR absorptions published in Organic Chemistry (Janice, 2008) and Silverstein et al. (2005).

\section{Nuclear Magnetic Resonance (NMR)}

Nuclear Magnetic Resonance (NMR) spectrometry was performed using JEOL JNM-ECA 500 Spectrometer. The operating system was based on the method described by Efdi et al. (2010). Sample was dissolved in $0.8 \mathrm{~mL}$ chloroform $\mathrm{D} 1\left(\mathrm{CDCl}_{3}\right)$ and placed into NMR tube to a sample depth of $4 \mathrm{~cm}$ and the ${ }^{1} \mathrm{H}$ $(500 \mathrm{MHz})$ and ${ }^{13} \mathrm{C}(125 \mathrm{MHz})$ spectra were measured.
Chemical shifts were reported as $\delta$ units (ppm) with Tetramethysilane (TMS) as internal standard and coupling constants $(J)$ in Hz. Integration of the ${ }^{1} \mathrm{H}-\mathrm{NMR}$ and ${ }^{13} \mathrm{C}-\mathrm{NMR}$ data was performed by using DELTA version 5.0.4 software by JEOL. The identification of each ${ }^{1} \mathrm{H}$-NMR and ${ }^{13} \mathrm{C}$-NMR detected was based on the Table of Characteristic NMR absorptions published in Organic Chemistry (Janice, 2008) and with the guide of the possible proposed structure given by NIST library.

\section{Melting Point}

The melting point of the compounds isolated was determined using a melting point apparatus (Stuat model SMP3). Small amount of the sample was put into a small capillary tube and was inserted into the machine melting point heating bath. The heating process was monitored and the temperature at which the sample begins to melt and completely melted was recorded.

\section{Brine Shrimp (Artemia salina) Lethality Test}

The $\mathrm{LC}_{50}$ of the compound was determined using brine shrimp lethality test. The test was conducted using larvae of Artemia salina based on method developed by McLaughlin et al. (1998). One spatula full of brine eggs was placed into a $250 \mathrm{~mL}$ beaker containing $150 \mathrm{~mL}$ of sea water placed under light environment. A source of $\mathrm{O}_{2}$ supply was connected to the beaker using water pump at reduced pressure and allowed for $72 \mathrm{~h}$ to hatch. The brine shrimp (nauplii) were then used for the test. Exactly $4 \mathrm{mg}$ of each Compound was dissolved in $200 \mu \mathrm{L}$ of DMSO (RCI Labscan limited) and a lower series of chosen concentration was prepared by serial dilution with DMSO. The assay system was prepared with $5 \mathrm{~mL}$ of filtered seawater containing chosen concentration of the compound and $1 \%$ yeast extract (for feeding) in a pre-marked 6-well microplate and 10 brine shrimps were carefully taken with micropipette and introduced into each microplate. This was done in triplicates making a total of 30 brine shrimps per concentration. Filtered seawater was added to DMSO and 10 brine shrimps in triplicates and this was used as the control groups. If the brine shrimp in these microplates shows a rapid mortality rate, then the test is considered invalid as the nauplii might have died due to some reasons other than the cytotoxicity of the isolated compound. The setup was allowed to remain for $24 \mathrm{~h}$ under constant illumination of fluorescent and number of survived nauplii were counted with a hand lens. Based on the data obtained, the average death of the brine shrimp at different concentrations of the extract and the $\mathrm{LC}_{50}$ of the extract was calculated using probit regression by statistical software SPSS 22 and the result was expressed as mean + SD at the $95 \%$ level of confidence $(p<0.05)$. 


\section{2,2-Diphenyl-1-Pricyl-Hydrazyl (DPPH) Free Radical Scavenging Assay (Antioxidant)}

The free radical scavenging assay of 2,2-Diphenyl-1Pycryl-Hydrazyl (DPPH) was used to evaluate the antioxidant properties of the Methyl biphenyl-4Carboxylate (1) and Methyl salicylate (2). The measurement was based on the method described by Wang et al. (2008) with little modification. The isolated compounds were prepared by diluting $5 \mathrm{mg}$ of the pure compound into $5 \mathrm{~mL}$ of methanol, producing a concentration of $1000 \mu \mathrm{g} / \mathrm{mL}$. The stock solution was sonicated to ensure the homogeneity of the sample. Three other concentrations were prepared at 25, 50 and 100 $\mu \mathrm{g} / \mathrm{mL}$ from the $1000 \mu \mathrm{g} / \mathrm{mL}$.

Approximately $3 \mathrm{~mL}$ of $0.1 \mathrm{mM}$ solution of 2,2diphenyl-1-Pycrylhydrazyl (DPPH) in methanol was each added into three series of prepared concentrations $(25,50$ and $100 \mu \mathrm{g} / \mathrm{mL})$ of sample solutions $(1 \mathrm{~mL})$. Analysis was done in triplicate. The solution was mixed vigorously and left to stand at room temperature for $30 \mathrm{~min}$ in the dark after which its absorbance was measured spectrophotometrically at $517 \mathrm{~nm}$ using Jasco ultra violet spectrophotometer model V-630. Methanol was used as blank (only methanol) and negative control (1 mL methanol mixed with $3 \mathrm{~mL}$ DPPH), while ascorbic acid (vitamin C) as the standard. The concentration of the sample required to inhibit $50 \%$ of the DPPH free radical was calculated as IC50 and the value was determined using Log dose inhibition curve which performed by using PRISM version 3.02 software, based on the calculated values of the DPPH scavenging activity (\%) of the sample (Tailor and Goyal, 2014).

\section{Antibacterial Assay}

Bacterial strains Escherichia coli, Salmonella typhii and Klebsielia pneumonia were selected for the study.
The bacterial strains were obtained from the Microbiology Laboratory, Faculty of Resource Science and Technology, Universiti Malaysia Sarawak and were used for the antibacterial activities. The stock cultures were incubated at $37^{\circ} \mathrm{C}$ for $24 \mathrm{~h}$ on nutrient agar (Micro care Laboratory, Surat, India) and was stored at $4^{\circ} \mathrm{C}$. Plates containing Mueller-Hinton Agar (MHA) were used to grow the bacterial strains at $37^{\circ} \mathrm{C}$. The stock cultures were then kept at $4^{\circ} \mathrm{C}$ until use.

Antibacterial activity of root extracts Leptadenia hastata was determined against three pathogenic bacterial strains using disk diffusion method as reported by various authors (Boyan et al., 2005; Prashanth et al., 2006). The extract was dissolved using Dimethyl Sulfoxide (DMSO) and sterilized by filtration and stored at $4^{\circ} \mathrm{C}$ until use. Standard antibiotics (tetracycline) was used for comparison of the zone of inhibition of the pure strains of the bacteria. The extracts were then screened for their antibacterial activity against the bacterial strains. Set of three dilutions for antibacterial activity $(25,50,100 \mu \mathrm{g} / \mathrm{mL})$ of the pure compound from the root extracts of Leptadenia hastata and standard drug (tetracycline) was used for the study. Sterile plates containing Mueller-Hinton agar were seeded with indicator bacterial strains and control experiment using tetracycline as standard drug were kept for $3 \mathrm{~h}$ at $37^{\circ} \mathrm{C}$. They were then incubated for 18 to $24 \mathrm{~h}$ at $37^{\circ} \mathrm{C}$ and the zones of growth inhibition around the discs were measured in $\mathrm{mm}$. The antibacterial activity of the test organisms on the compounds were determined by measuring the diameter of the inhibitory zones on the surface of the agar around the discs. The experiment was carried out in triplicate and the mean values of the diameter of zones of inhibition was calculated using statistical software SPSS 22.
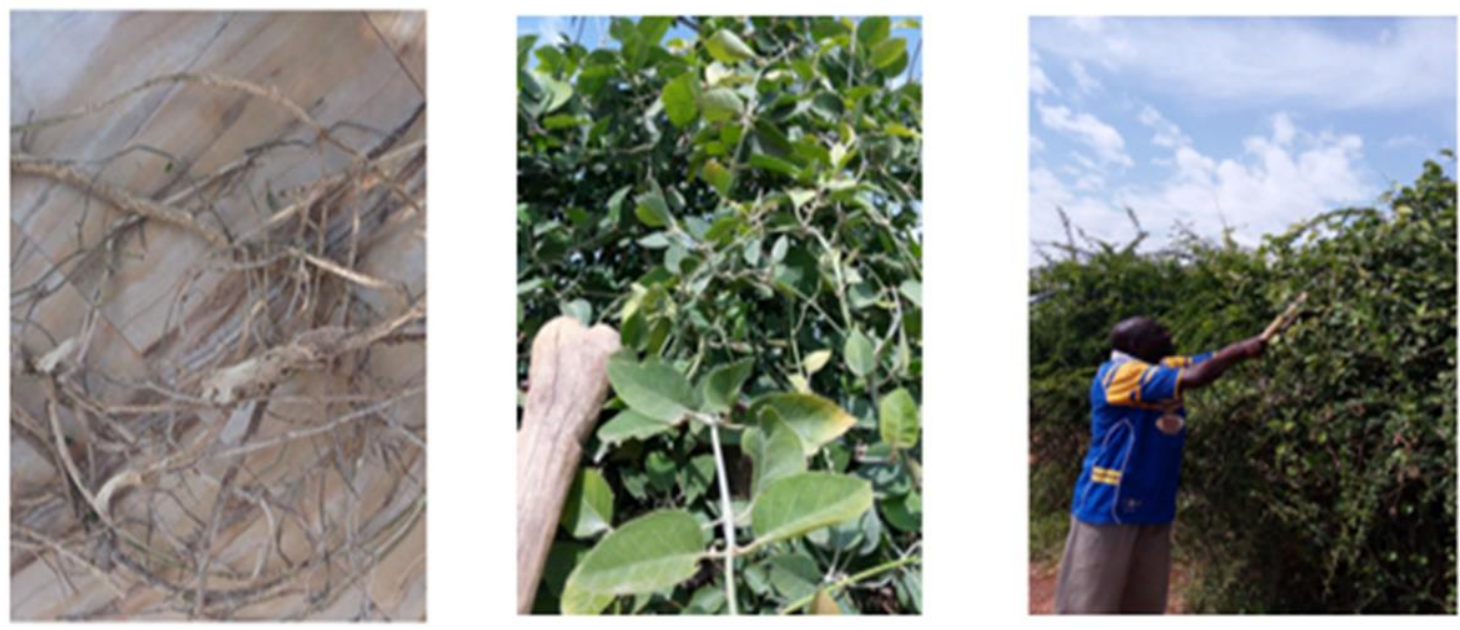

Fig. 1: Shows the Leptadenia hastata dried roots and natural habitats 


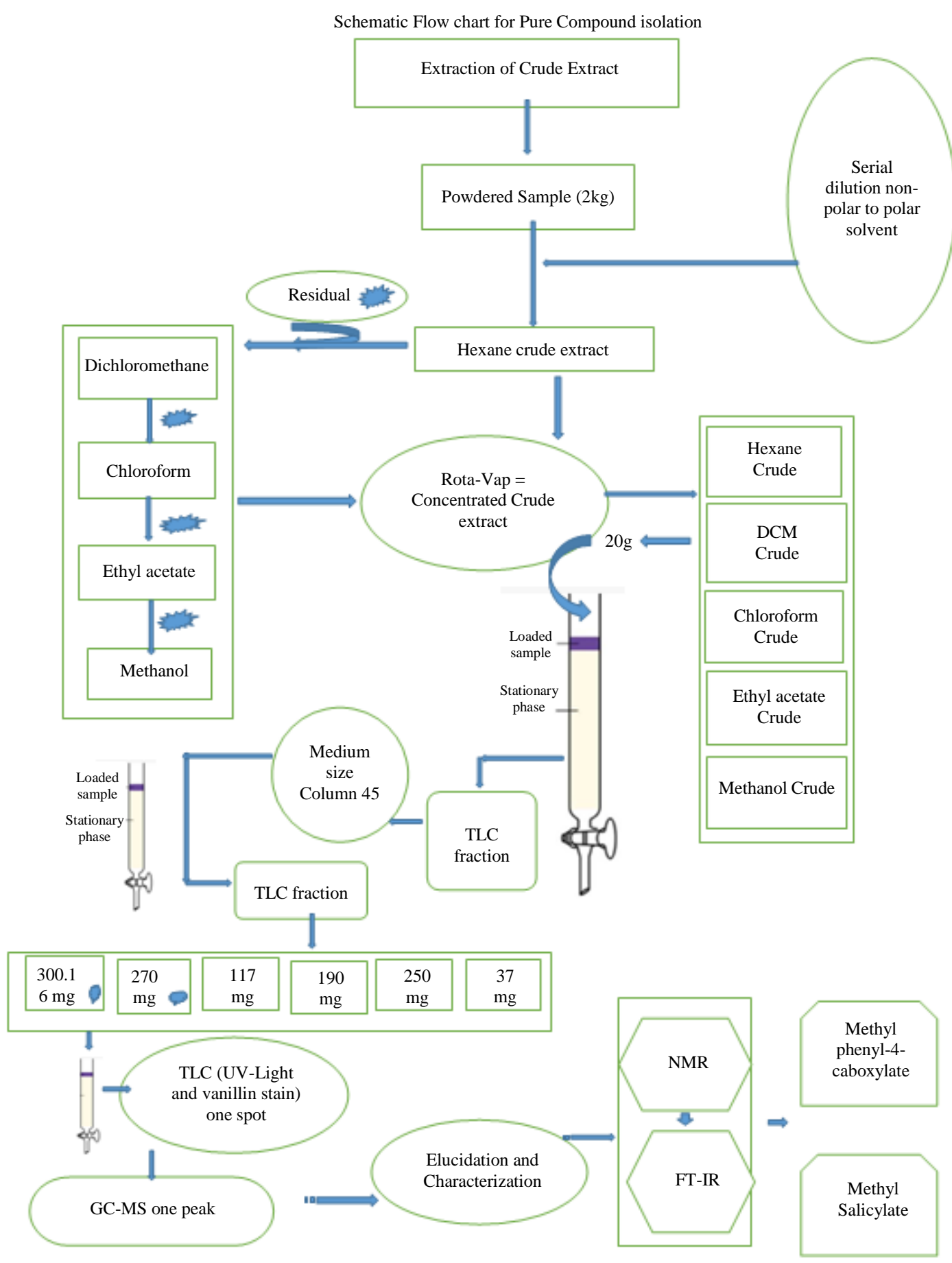

Fig. 2: Flow chart for Pure Compound isolation

Compound 1 was isolated from Fraction LHLDCM 9 of $300.16 \mathrm{mg}$ with a dark green colour of Leptadenia hastata. Extract (LHLDCM9) was subjected to TLC and a dark spot was observed which was targeted and purified. The separation was done using a medium column and the TLC analysis of the collected fraction was performed and observed under UV light and three spot were observed showing a clear distinction for dichloromethane: chloroform solvent ratio. The result of the TLC was recorded as in Table 1.

The fractions containing clear separation with similar $R_{f}$ value were combined and was labelled as LHLDCM9-A. TLC of the combined fraction LHLDCM9-A was performed in a different solvent 
system. Dichloromethane: Chloroform (8:2) was used as the solvent system for further purification of the combined fractions of LHLDCM9-A using a smaller column. TLC of the collected fractions were further subjected to UV light the identification of single spot. Two fractions were obtained with one spot each having similar $R_{f}$ value and renamed LHLDCM9-A2 and LHDCM9-A3. They were combined and labelled as LHLDCM9-A4. The TLC of the fraction was performed and recorded in Table 2 .

Figure 3 shows the TLC profile for the combined fraction LHDCM9-A4 in dichloromethane: ethyl acetate (9:1) as a single spot which indicates that is a pure compound.

LHDCM9-A4 analysis in GC was performed and the result obtained revealed a single peak at a retention time of $23.013 \mathrm{~min}$. Figure 4 revealed the single peak of LHLDCM9-A4 and was renamed as Compound 1. The weight of the compound obtained was $15.5 \mathrm{mg}$ and the physical appearance is clear solid white substance.

\section{Structural Elucidation of Compound}

Compound 1 was isolated as white solid with a melting point of $154^{\circ} \mathrm{C}$ with a mass spectrum as shown in Fig. 5. This Compound showed similarity index of $93.16 \%$ with the mass spectrum suggested by NIST library as well as the ion base peak which appeared at $m / z 212$, as well as on the mass spectrum of the suggested structure Fig. 6 which corresponded to the molecular weight of the Compound 1 with chemical formula $\mathrm{C}_{13} \mathrm{H}_{12} \mathrm{~N}_{2} \mathrm{O}$.

The IR spectrum of Compound 1 (Fig. 7) suggest that the chemical structure of Compound 4 has a carbonyl group $\mathrm{C}=\mathrm{O}$ which appeared at $1791 \mathrm{~cm}^{-1}$. The IR also indicated the presence of methylene stretching bonds at $2977 \mathrm{~cm}^{-1}$ and $878 \mathrm{~cm}^{-1}$, respectively. A signal was also observed at $1047 \mathrm{~cm}^{-1}$ indicating the presence of $\mathrm{C}-\mathrm{O}$ bond. The IR spectrum also showed similarity to the IR stretching and bending of the same compound as reported in the Supplementary Materials (2014).
The identification of Compound 1 was further confirmed by the NMR analysis. Further elucidation as represented in Fig. 8. ${ }^{1} \mathrm{H}-\mathrm{NMR}$ spectrum of the proposed structure of Compound 1. The proton of Compound 1 was integrated and assigned to the proposed chemical structure which is reported in Table 3. This agrees with ${ }^{1} \mathrm{H}-\mathrm{NMR}$ characteristic absorption and ${ }^{1} \mathrm{H}-\mathrm{NMR}$ splitting reported in spectrometric identification of Organic compounds by Silverstein et al. (2005) and Janice (2008).

${ }^{1} \mathrm{H}-\mathrm{NMR}$ spectrum revealed that the chemical structure of Compound 1 exhibited 12 proton resonates, a strong signal proton was observed at $\delta 3.89(3 \mathrm{H}, \mathrm{s})$ and was assigned to $\mathrm{H}-16$ which indicated the presence of methyl proton in the structure of Compound 1. Protons were observed at $\delta 7.47-7.63(\mathrm{~m}, 3 \mathrm{H})$ and were assigned to $\mathrm{H}-8$ to $\mathrm{H}-11$. A doublet proton was observed at $\delta 8.11$ $8.09(\mathrm{~d}, 2 \mathrm{H}, \mathrm{J}=8.10)$ and $\delta 7.65-7.70(\mathrm{~d}, 2 \mathrm{H}, \mathrm{J}=7.67)$ and were assigned to $\mathrm{H}-2 / \mathrm{H}-3$ and $\mathrm{H}-5 / \mathrm{H}-6$ respectively.

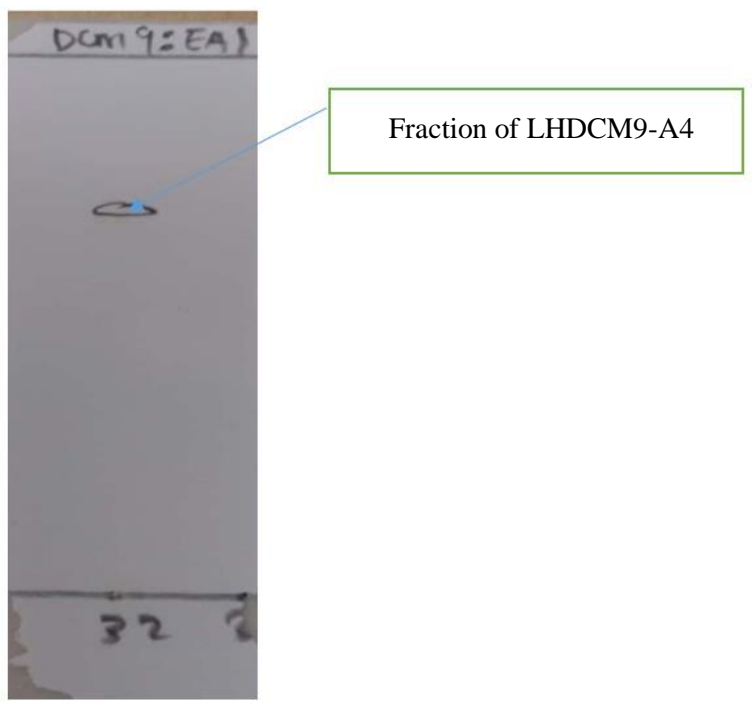

Fig. 3: TLC plate showing the spots in combined fraction of LHLDCM9-A4 in dichloromethane: Ethyl acetate (9:1)

Table 1: TLC and $R_{f}$ values of combined fraction of LHDCM9 in different solvent system under UV light

\begin{tabular}{llll}
\hline Solvent system (v/v) & Number of spots on TLC & $R_{f}$ value & Stained TLC colour \\
\hline Dichloromethane: Chloroform (7:3) & 4 & 0.42 & Light green \\
& & 0.21 & 0.45 \\
& & 0.63 & Colourless \\
Dichloromethane: Chloroform (8:2) & 3 & 0.55 & 0.13 \\
& & 0.10 & Colourless \\
Dichloromethane: Chloroform (9:1) & 2 & 0.36 & 0.47 \\
\hline
\end{tabular}

Table 2: TLC and $R_{f}$ values of combined fraction of LHLDCM9-A4 in different solvent system under UV light

\begin{tabular}{lllll}
\hline Combined fraction & Solvent system (v/v & Number of spots & $R_{f}$ value & Colour \\
\hline LHDCM9-A4 & Dichloromethane: Ethylacetate 9:1 & 1 & 0.62 & Colourless \\
\hline
\end{tabular}


Table 3: Proton NMR signal of compound 1 and that reported by Supplementary material, (2014)

\begin{tabular}{llll}
$\begin{array}{l}\text { Proton assigned } \\
\text { to compound 1 }\end{array}$ & $\begin{array}{l}\text { Proton chemical shift } \\
(\mathrm{ppm}) \text { of compound 1 }\end{array}$ & $\begin{array}{l}\text { Proton assigned to methyl } \\
\text { biphenyl-4-caboxylate } \\
\text { (Supplementary Materials, 2014) }\end{array}$ & $\begin{array}{l}\text { Mo } \\
\text { caboxylate (Supplementary } \\
\text { Materials, 2014) }\end{array}$ \\
\hline H-2-H 3 & $8.11-8.09(1 \mathrm{H}, \mathrm{d})$ & $\mathrm{H}-2-\mathrm{H} 3$ & $7.80-8.02(1 \mathrm{H}, \mathrm{d})$ \\
H-5/H-6 & $7.65-7.70(1 \mathrm{H}, \mathrm{d})$ & $\mathrm{H}-5 / \mathrm{H}-6$ & $7.72-7.99(1 \mathrm{H}, \mathrm{d})$ \\
H-8-H11 & $7.47-7.63(1 \mathrm{H}, \mathrm{m})$ & $\mathrm{H}-8-\mathrm{H} 11$ & $7.46-7.67(\mathrm{~m}, 3 \mathrm{H})$ \\
$\mathrm{H}-12$ & $7.67(1 \mathrm{H}, \mathrm{d} J=7.67)$ & $\mathrm{H}-12$ & $7.67(\mathrm{~d}, 2 \mathrm{H})$ \\
H-15 & $3.89(\mathrm{~m}, 3 \mathrm{H}, J=3.92)$ & $\mathrm{H}-15$ & $3.84(\mathrm{~s}, 3 \mathrm{H})$ \\
\hline
\end{tabular}

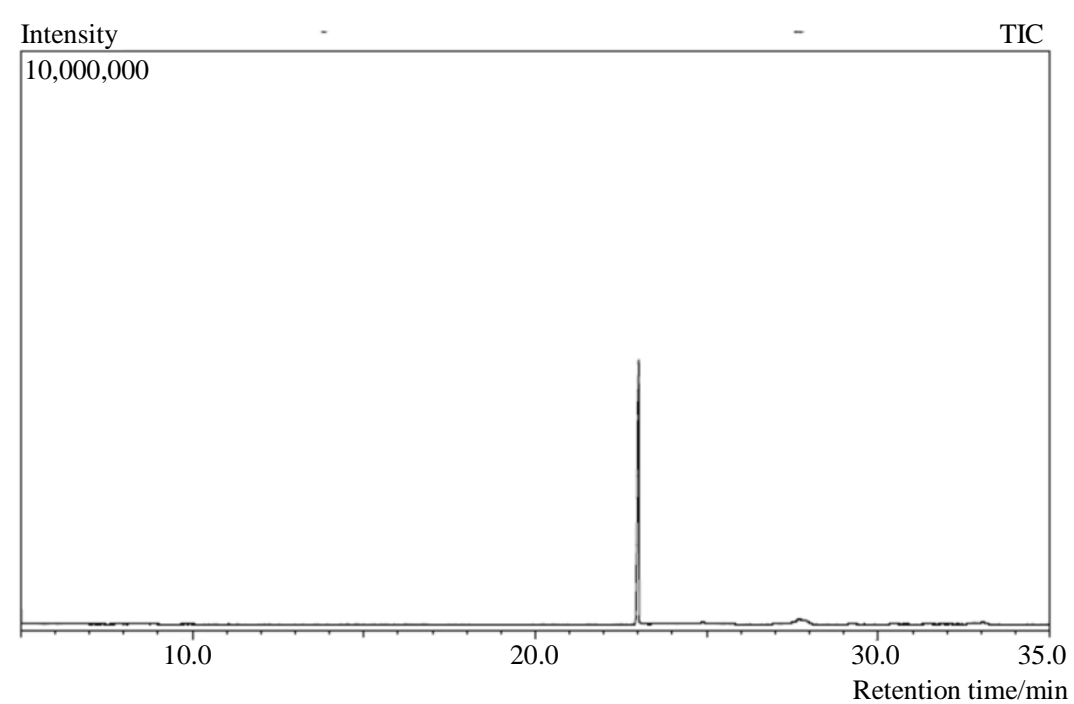

Fig. 4: Gas chromatogram of compound 1

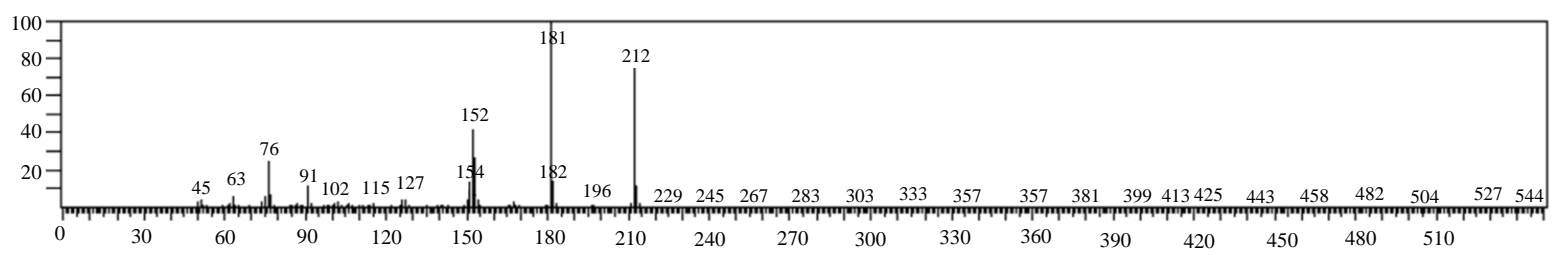

Fig. 5: Mass spectrum of compound 1

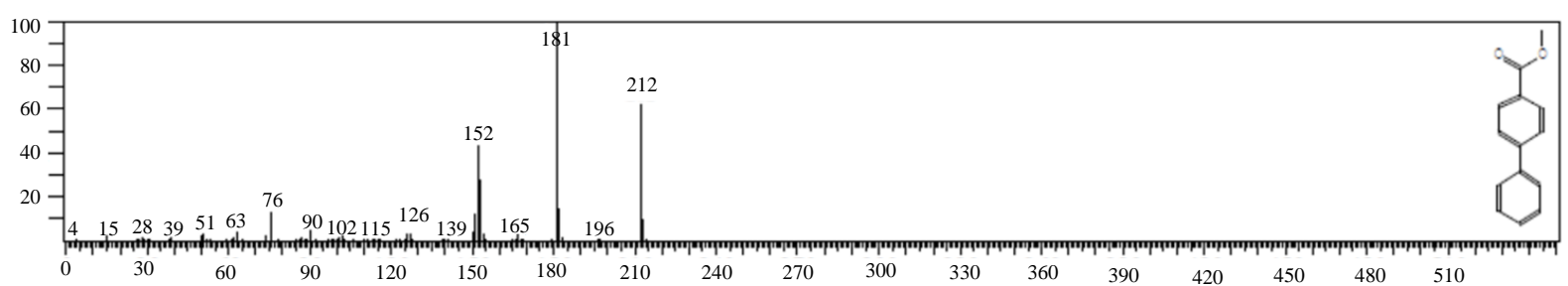

Fig. 6: Mass spectrum of suggested structure of compound 1 by the NIST library

The result from the ${ }^{13} \mathrm{C}-\mathrm{NMR}$ of Compound 1 is reported in Fig. 9. Every carbon was assigned to the proposed chemical structure which was based on the table of ${ }^{13} \mathrm{C}$-NMR characteristics absorption as reported in spectrometric identification of Organic compounds by Silverstein et al. (2005) and Janice (2008).
The ${ }^{13} \mathrm{C}-\mathrm{NMR}$ analysis and assignation of every carbon NMR to the proposed chemical structure of Compound 1 indicated the presence of 14 carbon resonates in the chemical structure. A signal was recognized at the chemical shift of $\delta 52.63$ which showed the presence of terminal methyl carbon attached 
to the carboxylate at the up field and was attached to $\mathrm{C}$ 16. In the down field 13 carbon was identified and were assigned. A long peak signal observed at down field as $\delta$ $130.18, \delta 129.00, \delta 127.13$ and $\delta 127.36$ and was assigned to $\mathrm{C}-11, \mathrm{C}-4, \mathrm{C}-5$ and $\mathrm{C}-6$ respectively. which were recognized as methylene carbon. The spectrum shown a recognizable peak identified as carbonyl group at $\delta 128.22$ which was assigned to $\mathrm{C}-12$.

The chemical shift of ${ }^{1} \mathrm{H}-\mathrm{NMR}$ and ${ }^{13} \mathrm{C}-\mathrm{NMR}$ for Compound 1 are shown as in Table 3 and Table 4 together with the reference data as reported in the Supplementary Materials (2014).

This data in tables 3 and 4 are chemical shift of proton and carbon NMR for Compound 1 which are used for identification and elucidation of the structure. The result used in the identification of Compound $1{ }^{1} \mathrm{H}-\mathrm{NMR}$ and ${ }^{13} \mathrm{C}$-NMR was supported by the spectrum data from the published literature which shows that the ${ }^{1} \mathrm{H}-\mathrm{NMR}$ and ${ }^{13} \mathrm{C}-\mathrm{NMR}$ of Compound 1 have similar result with one obtained from Methyl phenyl-4-caboxylate (1) in the Supplementary Materials (2014).

Compound 1 have similarity index of $93.16 \%$ as when compared with the mass spectrum of the suggested structure known as Methyl biphenyl-4-carboxylate (1) as suggested by NIST library. The Compound 1 is shown to have nine methylene, one methyl attached to Carbonyl and one attached to the carboxyl as well as three saturated carbon attached to the asymmetric benzene ring. The spectral shown for Compound 1 is reported to have similar result with that reported in the Supplementary Materials (2014).

With the data analysis from IR, ${ }^{1} \mathrm{H}-\mathrm{NMR},{ }^{13} \mathrm{C}-\mathrm{NMR}$ and with the one compared from the published literature Supplementary Materials (2014). Compound 1 was identified as Methyl biphenyl-4-carboxylate (1) which have chemical formula as $\mathrm{C}_{14} \mathrm{H}_{12} \mathrm{O}_{2}$.<smiles>COC(=O)c1ccc(-c2ccccc2)cc1</smiles>

1

Methyl biphenyl-4-carboxylate (62) has been reported to have the ability to inhibited Catechol- $O$ methyl transferase inhibitor as well as methyl guanidine inhibitor (Jamaluddin and Jones, 2005).

\subsubsection{Purification and Structural Elucidation of Compound 2}

\section{Purification}

Compound 2 was obtained from the dichloromethane roots crude extract. LHRDCM -10 of $270 \mathrm{mg}$ as a fraction from the crude extract, the targeted spot was further purified. Separation were done using column chromatography at solvent ratio dichloromethane: ethyl acetate (2:8). TLC analysis of the fraction obtained was subjected to UV Light for possible separation of compound into various $R_{f}$ fraction.

Spots on the TLC containing the same $R_{f}$ value were combined and rename as LHRDCM10-B as shown in Table 5. The combined fraction LHRDCM10-B was further subjected to smaller column for possible separation of one spot. Dichloromethane: Ethyl acetate (3:7) was used as the solvent for purification of the combined fraction. TLC of the fraction collected were again observed under UV light and fraction containing spots of interest were combined and labelled as LHRDCM10-B1. TLC of fraction LHRDCM10-B1 was performed using different solvent system as shown in Table 6.

Dichloromethane: chloroform (2:8) showed single peak, the collected sample was then repeated and the TLC subjected to UV-Light the fraction showed one single spot as shown in Table 7

Figure 10 Shows the TLC profile of the combined fraction LHRDCM10-B2 in DCM: Chloroform (2:8) as a single spot which suggest that it is a pure compound.

GC analysis of the fraction LHRDCM10-B2 result obtained from the gas chromatogram revealed a single peak at the retention time of $12.565 \mathrm{~min}$ as shown in Fig. 11. This confirmed that LHRDCM10-B2 is a pure compound thus renamed as Compound 2. The weight of the pure compound obtained $19.5 \mathrm{mg}$ and the physical appearance as a white

\section{Structural Elucidation}

Compound 2 was isolated from the dichloromethane crude extract of Leptadenia hastata roots. The physical appearance of Compound 2 is white crystal powder with melting point of $216^{\circ} \mathrm{C}$ as reported in the literature by Jadrijevic-Mladar and Vikic (2004). The mass spectrum of Compound 2 shown in Fig. 12 have a similarity index of $88.05 \%$ with the mass spectrum of the structure suggested by the NIST library in Fig. 13. An ion base peak was shown at $\mathrm{m} / \mathrm{z} 120$ on the Compound 2 mass spectrum, which appear to have the same ion base peak m/z 120 with that suggested spectrum by the NIST library. It also shows a molecular ion peak at $\mathrm{m} / \mathrm{z} 152$ which correspond with the same molecular ion peak and molecular ion weight of the suggested pure compound with a chemical formula $\mathrm{C}_{8} \mathrm{H}_{8} \mathrm{O}_{3}$.

The IR spectrum of Compound 2 (Fig. 14) consist of functional group $\mathrm{O}-\mathrm{H}$, which appeared at $3328.96 \mathrm{~cm}^{-1}$. An absorption band of C-H was observed at $2973.35 \mathrm{~cm}^{-1}$ and $2849.14 \mathrm{~cm}^{-1}$ which suggest the presence of methyl carbon in the chemical structure. An absorption was observed at $1653.85 \mathrm{~cm}^{-1}$ which represent a carbonyl group $\mathrm{C}=\mathrm{O}$. Another absorption band was observed at $1484.12 \mathrm{~cm}^{-1}$ which suggest the presence of $\mathrm{C}=\mathrm{C}$ aromatic double bond stretch. At $1055.04 \mathrm{~cm}^{-1}$ a strong C-O stretch was observed in the IR spectrum of Compound 2. 
Table 4: Carbon NMR signal of Compound 1 and that reported by Supplementary Materials (2014)

\begin{tabular}{|c|c|c|c|}
\hline $\begin{array}{l}\text { assigned } \\
\text { to compound } 1\end{array}$ & $\begin{array}{l}\text { Proton chemical shift } \\
\text { (ppm) of compound } 1\end{array}$ & $\begin{array}{l}\text { Proton assigned to methyl } \\
\text { biphenyl-4-caboxylate } \\
\text { (Supplementary Materials, 2014) }\end{array}$ & $\begin{array}{l}\text { Proton chemical shift (ppm) } \\
\text { of methyl biphenyl-4-Proton } \\
\text { caboxylate (Supplementary } \\
\text { Materials, 2014) }\end{array}$ \\
\hline $\mathrm{C}-1$ & 145.74 & $\mathrm{C}-1$ & 145.16 \\
\hline $\mathrm{C}-2$ & 127.40 & C-2 & 127.40 \\
\hline C-3 & 127.26 & C-3 & 127.10 \\
\hline C-4 & 129.00 & C-4 & 128.89 \\
\hline C-5 & 127.13 & C-5 & 127.13 \\
\hline C-6 & 127.36 & C- 6 & 127.36 \\
\hline C-7 & 140.10 & C-7 & 139.29 \\
\hline C-8 & 128.36 & C- 8 & 127.45 \\
\hline C-9 & 130.78 & C-9 & 130.28 \\
\hline C-10 & 127.35 & C-10 & 127.60 \\
\hline C-11 & 130.18 & C-11 & 129.58 \\
\hline C-12 & 128.22 & C-12 & 127.43 \\
\hline C-13 & 167.12 & C-13 & 166.53 \\
\hline $\mathrm{C}-16$ & 52.210 & C-16 & 52.630 \\
\hline
\end{tabular}

Table 5: TLC and $R_{f}$ values of combined fraction of LHRDCM10-B in different solvent system under UV light

\begin{tabular}{llll}
\hline Solvent system (v/v) & Number of spots & $R_{f}$ value & Stained TLC colour \\
\hline DCM: Chloroform (3:7) & 3 & 0.67 & Colourless \\
& & 0.20 & 0.18 \\
DCM: Ethyl acetate (3:7) & 3 & 0.59 & Colourless \\
& & 0.33 & 0.27 \\
\hline
\end{tabular}

Table 6: TLC and $R_{f}$ values of combined fraction of LHRDCM10-B1 in different solvent system under UV light

\begin{tabular}{llll}
\hline Solvent system (v/v) & Number of spots & $R_{f}$ value & Stained TLC colour \\
\hline DCM: Chloroform (2:8) & 1 & 0.69 & Colourless \\
DCM: Ethyl acetate (1:9) & 2 & 0.58 & Colourless \\
\end{tabular}

Table 7: TLC and $R_{f}$ values of combined fraction of LHRDCM10-B2 in different solvent system under UV light

\begin{tabular}{llll}
\hline Solvent system $(\mathrm{v} / \mathrm{v})$ & Number of spots & $R_{f}$ value & Stained TLC colour \\
\hline DCM: Chloroform $(2: 8)$ & 1 & 0.70 & Colourless \\
\hline
\end{tabular}

In NMR analysis further chemical analysis was performed, integration and assignation of every proton NMR of Compound 2 to the proposed chemical structure $\mathrm{C}_{8} \mathrm{H}_{8} \mathrm{O}_{3}$ based on the table of ${ }^{1} \mathrm{H}-\mathrm{NMR}$ characteristics absorption and peak's splitting pattern as reported in spectrometric identification of Organic Compounds by Silverstein et al. (2005) and Janice (2008) was considered.

Five proton signals were observed and assigned, a doublet proton signal was observed at $\delta 7.01(2 \mathrm{H}, \mathrm{d}), \delta$ $7.53(1 \mathrm{H}, \mathrm{t})$ and $\delta 6.93(1 \mathrm{H}, \mathrm{t})$ and indicating the presence of methine group of the structure and was assigned to $\mathrm{H}-3, \mathrm{H}-4$ and $\mathrm{H}-5$ respectively. A doublet proton was observed at the chemical shift $\delta 7.92(1 \mathrm{H}, \mathrm{d})$ indicating the presence of methyl group of the structure. A signal was observed at $\delta 10.37$ which represent the functional hydroxyl group and assigned to $\mathrm{OH}$.

Assignation of carbon NMR of Compound 2 chemical structure is based on the data report in spectrometric identification of Organic compounds by Silverstein et al. (2005) and Janice (2008).

${ }^{13} \mathrm{C}$-NMR of Compound 2 as shown in Fig. 15a and $15 \mathrm{~b}$ was assigned to the total number of 8 signals. Four signal were observed at a chemical shift of $\delta$ $117.73, \delta 136.38, \delta 119.08$ and $\delta 130.90$ indicating the presence of methine group of the structure and were assigned to C-3, C-4, C-5 and C-6. A carbonyl group was observed at $\delta 174.69$ and was assigned to C-7. Also observed was $\delta 111.37$ a quaternary carbon and $\delta$ 162.28 as carbonyl group bearing the $\mathrm{OH}$ group and were assigned to $\mathrm{C}-1$ and $\mathrm{C}-2$, respectively. A methyl group at $\delta 26.34$ was observed and assigned to C-8.

Chemical shift of every proton and carbon for Compound 2 is shown in Table 8 and 9 as well as the reference with which comparison was made to have similar data as reported by Jadrijevic-Mladar and Vikic (2004). 
Table 8: Proton NMR signal of compound 2 and that reported by Jadrijevic-Mladar and Vikic (2004)

\begin{tabular}{llll}
\hline $\begin{array}{l}\text { Proton assigned to } \\
\text { compound 2 }\end{array}$ & $\begin{array}{l}\text { Proton chemical shift } \\
\text { (ppm) of compound 2 }\end{array}$ & $\begin{array}{l}\text { Proton assigned to methyl } \\
\text { salicylate (Jadrijevic-Mladar } \\
\text { and Vikic, 2004) }\end{array}$ & $\begin{array}{l}\text { Proton chemical shift (ppm) of } \\
\text { methyl salicylate (Jadrijevic- } \\
\text { Mladar and Vikic, 2004) }\end{array}$ \\
\hline $\mathrm{H}-3$ & $7.01(2 \mathrm{H}, \mathrm{d}, \mathrm{J}=7.5)$ & $\mathrm{H}-3$ & $6.96(\mathrm{~d}, \mathrm{~J}=7.5)$ \\
$\mathrm{H}-4$ & $7.53(3 \mathrm{H}, \mathrm{t}, \mathrm{J}=7.7)$ & $\mathrm{H}-4$ & $7.52(\mathrm{t}, \mathrm{J}=7.7)$ \\
$\mathrm{H}-5$ & $6.93(3 \mathrm{H}, \mathrm{t}, \mathrm{J}=7.4)$ & $\mathrm{H}-5$ & $6.92(\mathrm{t}, \mathrm{J}=7.4)$ \\
$\mathrm{H}-6$ & $7.92(2 \mathrm{H}, \mathrm{d}, \mathrm{J}=7.7)$ & $\mathrm{H}-6$ & $7.82(\mathrm{~d}, \mathrm{~J}=7.7)$ \\
$\mathrm{OH}$ & 10.37 & $\mathrm{OH}$ & 11.52 \\
\hline
\end{tabular}

Table 9: Carbon NMR signal of compound 2 and that reported by Jadrijevic-Mladar and Vikic (2004)

\begin{tabular}{llll}
\hline $\begin{array}{l}\text { Carbon assigned to } \\
\text { compound 2 }\end{array}$ & $\begin{array}{l}\text { Carbon chemical shift } \\
\text { (ppm) of compound 2 }\end{array}$ & $\begin{array}{l}\text { Carbon assigned to methyl } \\
\text { salicylate (Jadrijevic-Mladar } \\
\text { and Vikic, 2004) }\end{array}$ & $\begin{array}{l}\text { Carbon chemical shift } \\
\text { (ppm) of methyl salicylate } \\
\text { (Jadrijevic-Mladar and } \\
\text { Vikic, 2004) }\end{array}$ \\
\hline C-1 & 111.37 & C-1 & 113.02 \\
C-2 & 162.28 & C-2 & 161.29 \\
C-3 & 117.73 & C-3 & 117.21 \\
C-4 & 136.38 & C-4 & 135.76 \\
C-5 & 119.08 & C-5 & 119.28 \\
C-6 & 130.9 & C-6 & 130.4 \\
C-7 & 174.69 & C-7 & 172.08 \\
C-8 & 41.14 & C-8 & 51.5 \\
\hline
\end{tabular}

Table 10: The physicochemical properties of the isolated compounds

\begin{tabular}{lllllll}
\hline $\mathrm{s} / \mathrm{n}$ & Compound Name & M.formula & M.W & M.P $\left({ }^{\circ} \mathrm{C}\right)$ & $\mathrm{R}_{\mathrm{f}}$ values & $\%$ Yield \\
\hline 1 & Methylphenyl-4-aboxylate & $\mathrm{C}_{13} \mathrm{H}_{12} \mathrm{~N}_{2} \mathrm{O}_{2}$ & 121 & $216^{\circ} \mathrm{C}$ & 0.7 & $0.1 \%$ \\
2 & Methyl salicylate & $\mathrm{C}_{16} \mathrm{H}_{32} \mathrm{O}_{2}$ & 152 & $154^{\circ} \mathrm{C}$ & 0.6 & $0.1 \%$ \\
\hline
\end{tabular}

Table 11: Average death of brine shrimp (Artemia salina) at different concentrations of the pure compounds isolated

\begin{tabular}{|c|c|c|c|c|c|c|}
\hline \multirow[b]{2}{*}{ Isolated compounds } & \multicolumn{5}{|c|}{$\begin{array}{l}\text { Average death of brine shrimp } \\
\text { Concentration } \mathrm{ppm}(\mu \mathrm{g} / \mathrm{mL})\end{array}$} & \multirow[b]{2}{*}{$\mathrm{LC}_{50}(\mu \mathrm{g} / \mathrm{mL})$} \\
\hline & 1 & 5 & 10 & 50 & 100 & \\
\hline DMSO and Sea Water & $0.00+0.00$ & $0.00+0.00$ & $0.00+0.00$ & $0.00+0.00$ & $0.00+0.00$ & $0.00+0.00$ \\
\hline Thymol & $5 \pm 0.59$ & $7 \pm 0.23$ & $10 \pm 0.00$ & $10 \pm 0.00$ & $10 \pm 0.00$ & 1.16 \\
\hline Methyl biphenyl-4-Carboxylate & $3 \pm 0.35$ & $4 \pm 0.27$ & $5 \pm 0.47$ & $7 \pm 0.47$ & $10 \pm 0.00$ & 8.770 \\
\hline Methyl salicylate & $2 \pm 0.46$ & $3 \underline{ \pm} 0.47$ & $4 \pm 0.58$ & $5 \pm 0.59$ & $8 \pm 0.00$ & 23.982 \\
\hline
\end{tabular}

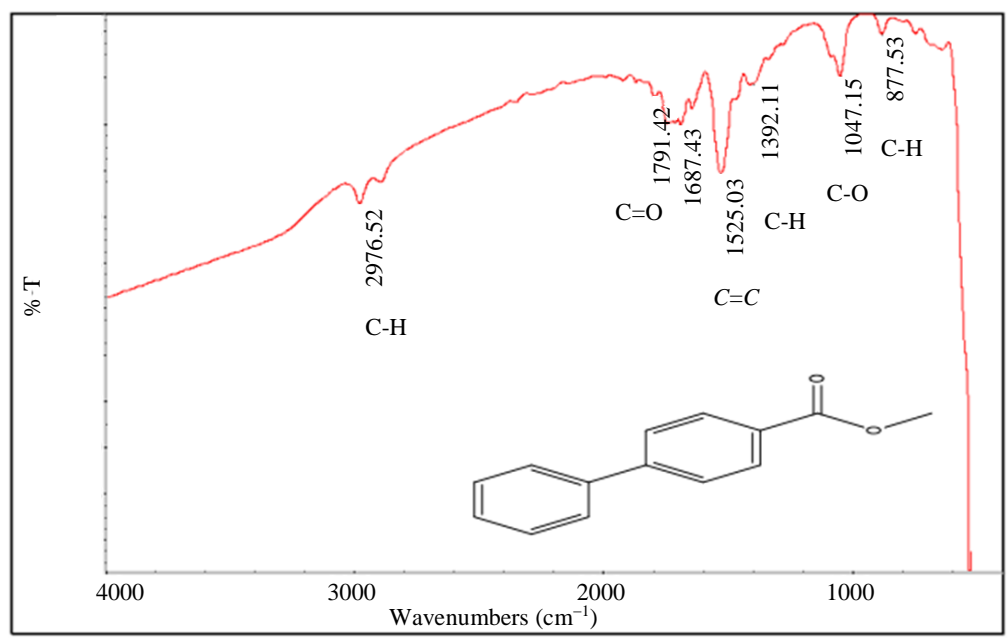

Fig. 7: IR structure of compound 1 
Isaac John Umaru and Hauwa A. Umaru / American Journal of Biochemistry and Bioztechnology 2019, 15 (4): 251.269 DOI: 10.3844/ajbbsp.2019.251.269

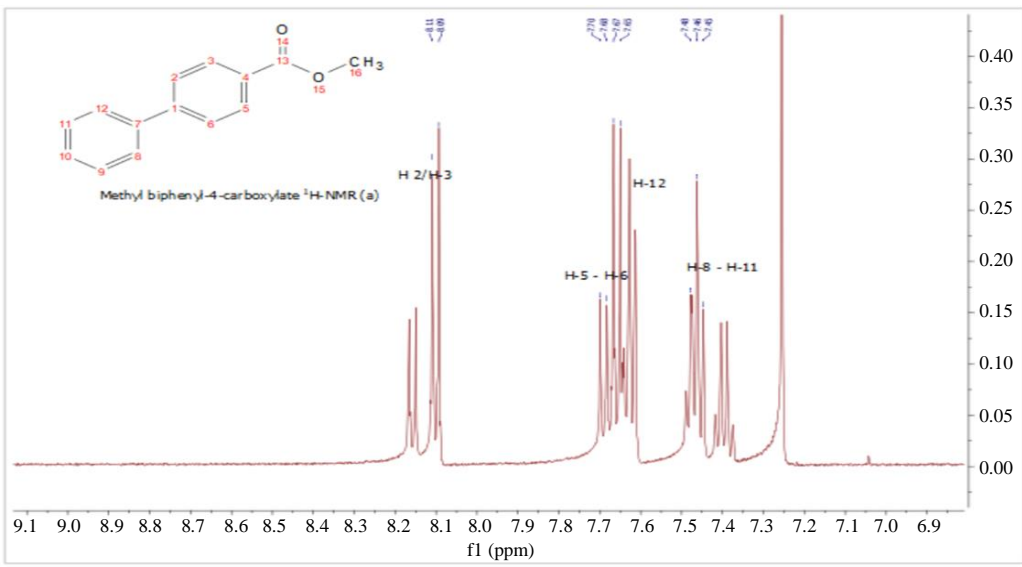

(a)

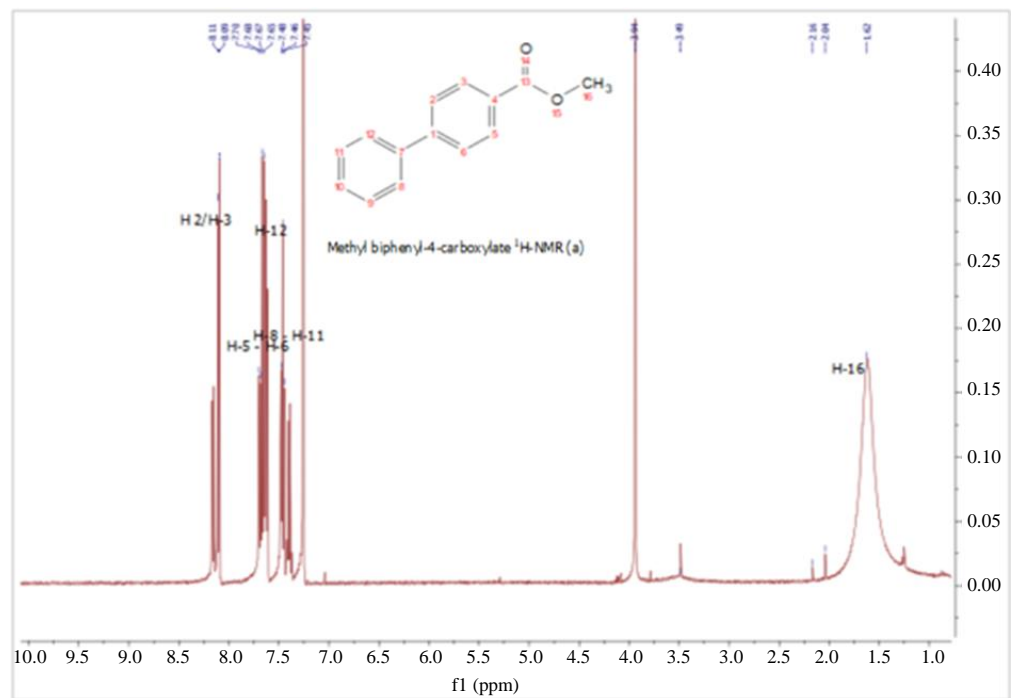

(b)

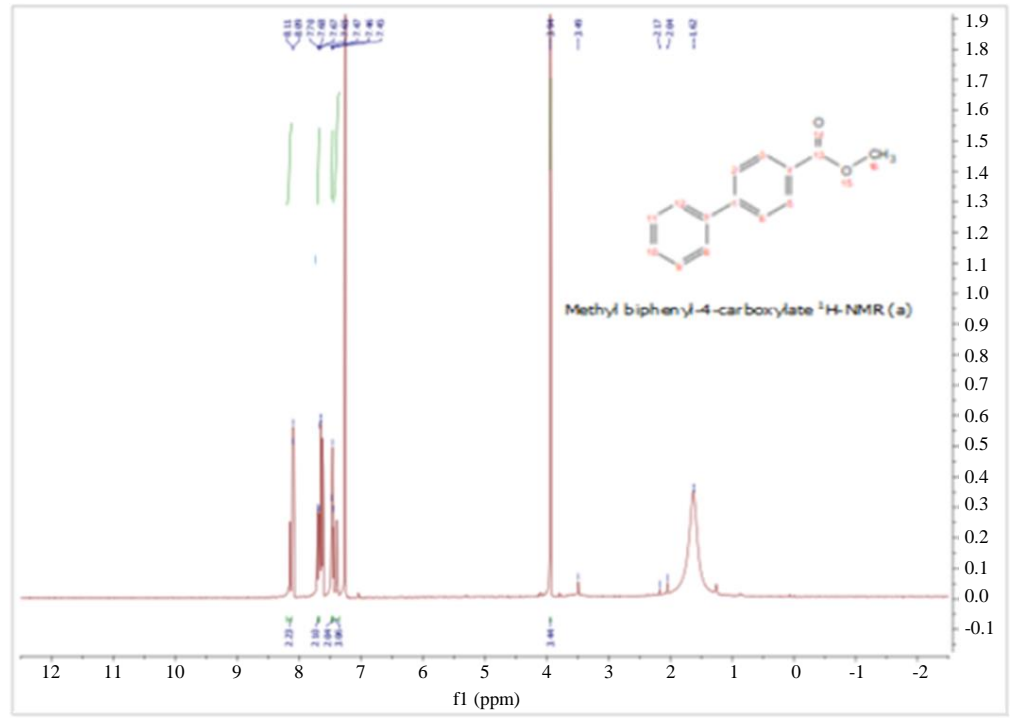

(c)

Fig. 8: (a) ${ }^{1} \mathrm{H}-\mathrm{NMR}$ spectrum of Compound $1\left(500 \mathrm{MHz}, \mathrm{CDCl}_{3}\right)$; (b) ${ }^{1} \mathrm{H}-\mathrm{NMR}$ spectrum of Compound $1\left(500 \mathrm{MHz}, \mathrm{CDCl}_{3}\right)(\mathrm{c}){ }^{1} \mathrm{H}-$ NMR spectrum of Compound $1\left(500 \mathrm{MHz}, \mathrm{CDCl}_{3}\right)$ ) 
Chemical shift of every ${ }^{1} \mathrm{H}-\mathrm{NMR}$ and ${ }^{13} \mathrm{C}$-NMR for Compound 2 and the data obtained from GC analysis gave similarity index of $88.05 \%$ with the mass spectrum of the suggested structure by NIST library with chemical formula $\mathrm{C}_{8} \mathrm{H}_{8} \mathrm{O}_{3}$. The melting point of Compound 2 was found to be $216-218^{\circ} \mathrm{C}$ (lit $218^{\circ} \mathrm{C}$ ) these characteristics matched with Compound thus confirm Compound 2 to be Methyl salicylate (2). Also observed to match was the IR data confirming the presence of the functional group Compound 2 when compared to the reference data as published by Jadrijevic-Mladar and Vikic Topic (2004).

Therefore, based on the IR, 1H-NMR and 13C-NMR it showed that the data matched the suggested chemical structure with the published data as Methyl salicylate (2).

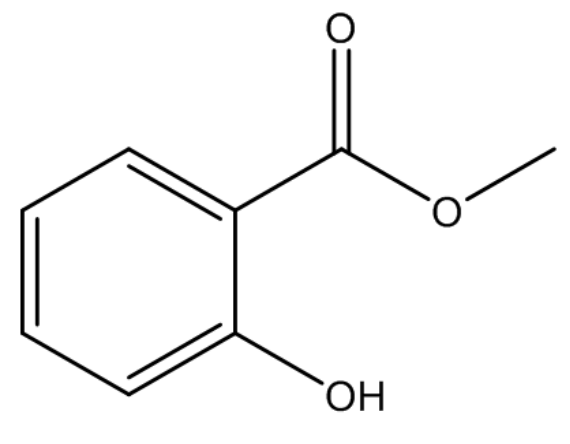

2

Methyl salicylate (2) is widely used in the food industry to give aromas to consumables manufactured in the industries (Filho et al., 1995).
Methyl salicylate (2) was reported to have analgesic, antipyretic and anti-inflammatory properties as well as provide therapeutic beneficial, it was found to inhibit platelet aggregation. The compound was also classified as one of the NSAIDs and are used as semi-products of biosynthesis of aromatic amino acids in plants (Phenolic acids). They are considered also as one of the metabolites of numerous exogenous toxic substance including drugs and endogenous catecholamine's. They are reported to be present in many medicine plants e.g., Matricaria recutita L Jadrijevic-Mladar and Vikic (2004).

The pharmacological potential of the compound as well as the side effect was as a result of the presence of the structural features and the active moiety site for the Cyclooxygenase (COX) inhibition which appears to be the salicylate anion, associated with the carboxylic acid functional group (Hacksell, 1996). The result is mean \pm SD. $\mathrm{N}=30$.

There was an observed concentration dependent increment in mortality rate of the Brine shrimp of all the pure compounds the lethality of a test of pure compound in a simple zoological organism such as the shrimp (Artemia salina) has been utilized in the Brine Shrimp Cytotoxicity Test (BSCT). It is a very useful tool to screen a wide range of chemical compounds for their various bioactivities (Asaduzzaman et al., 2015). The Brine Shrimp Lethality Bioassay also indicates antifungal effects, pesticidal effects, teratogenic effects, toxicity to environment (Sarah et al., 2017). The technique is cost effective and it require a small amount of sample and gives a predictive of cytotoxicity.

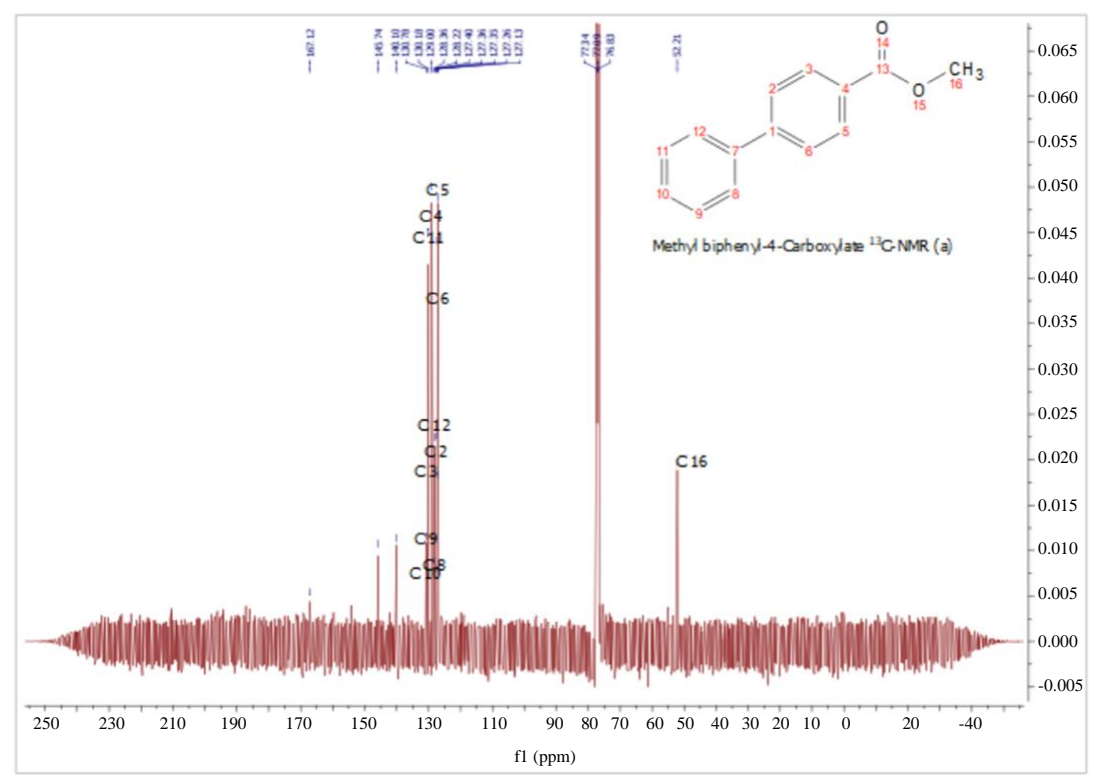

(a) 


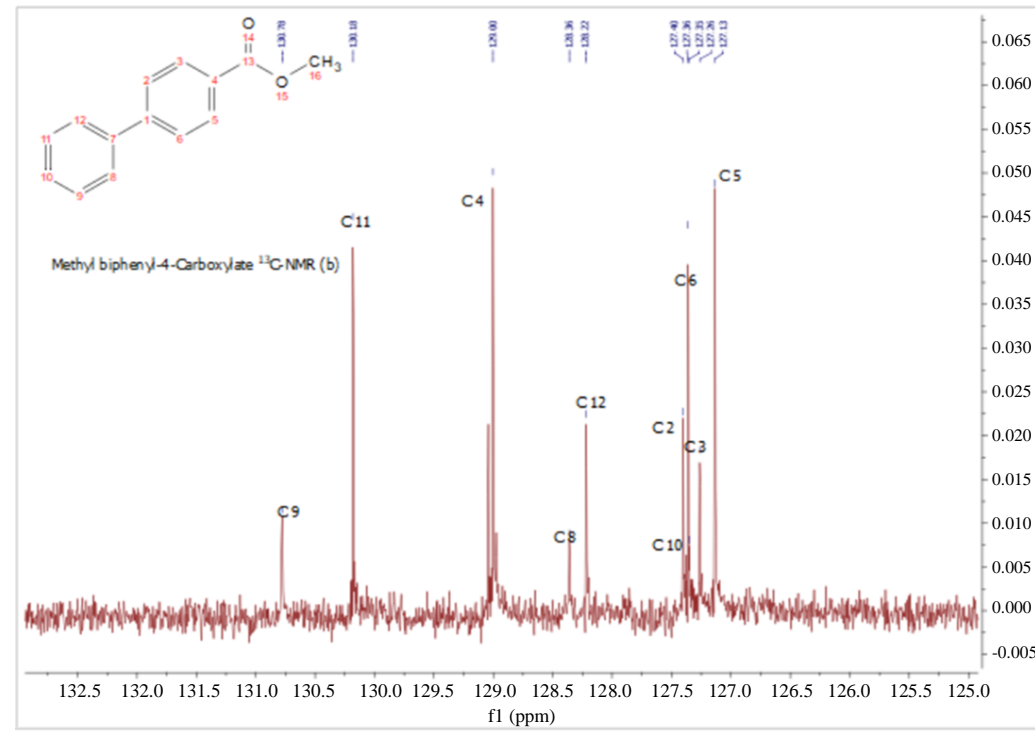

(b)

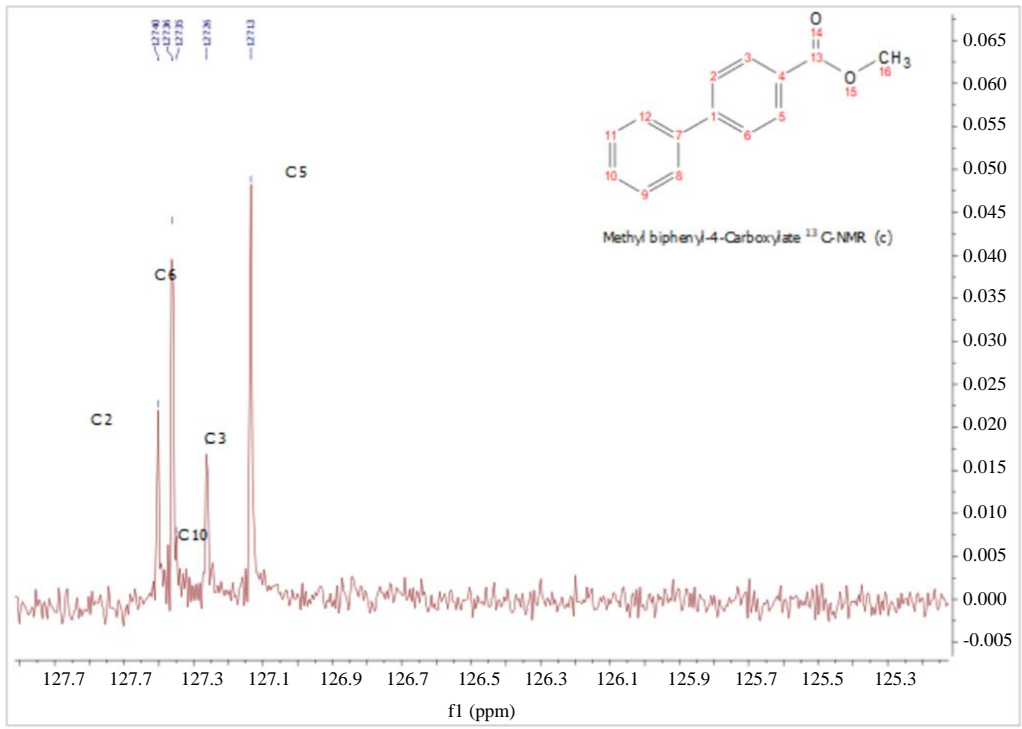

(c)

Fig. 9: (a) ${ }^{13} \mathrm{C}-\mathrm{NMR}$ spectrum of Compound 1 (125 MHz, $\left.\mathrm{CDCl}_{3}\right)$; (b) ${ }^{13} \mathrm{C}-\mathrm{NMR}$ spectrum of Compound 1 (125 $\left.\mathrm{MHz}, \mathrm{CDCl}_{3}\right)$; (c) ${ }^{13} \mathrm{C}-\mathrm{NMR}$ spectrum of Compound $1\left(125 \mathrm{MHz}, \mathrm{CDCl}_{3}\right)$

The aim of this method was to ascertain the base line screening of active chemical constituents for its lethality which has been proven to be a useful tool in screening various chemical constituents since its introduction by Meyer et al. (1982).

Analysis of Methyl biphenyl-4-Carboxylate (1) and Methyl salicylate (2) to determined their toxicity against the brine shrimp demonstrated the compounds to be concentration dependent in the mortality rate of the brine shrimp which agrees with the report of Patil et al. (2014).

Table 11 showed the cytotoxicity activity of the isolated pure compound Methyl biphenyl-4-Carboxylate (1) and Methyl salicylate (2). DMSO plus Sea Water was used as the negative control while Thymol as the positive control for the test.

The result indicated Methyl biphenyl-4-Carboxylate (1) to have exhibited highest lethality activity with $\mathrm{LC}_{50}$ value of $8.770 \mu \mathrm{g} / \mathrm{mL}$ and Methyl salicylate (2) at $23.982 \mu \mathrm{g} / \mathrm{mL}$ as shown in Table 11

However, Moshi et al. (2010) and Elumba et al. (2013) suggested that some toxicity with $\mathrm{LC}_{50}$ below $1000 \mu \mathrm{g} / \mathrm{mL}$ which are categorized as toxic, does not always indicate its danger or out-right toxicity toward human, but may also suggest a potential antitumor or anticancer activities. Thus, exposure or administering this type of compound may unlikely to have negative effects on human (Moshi et al., 2010). 
This agrees with the report of (Asaduzzaman et al., 2015) that brine shrimp lethality test gives a significant correlation between brine shrimp assay and in-vitro growth inhibition of human solid tumour cell lines as well the detect of antitumor compounds in terrestrial plant extracts. The result obtained on the cytotoxicity assays of the Methyl biphenyl-4-Carboxylate (1) and Methyl salicylate (2), it could as well be used in the synthesis of more drugs to avert human pathogens, antitumor as well as anticancer figures are in $\mathrm{mm}$ and include the diameter of the paper disc $(5 \mathrm{~mm})$. Data are means of triplicate determinations.

The antibacterial activity of the isolated compound 2Methyl biphenyl-4-Carboxylate (1) and Methyl salicylate (2) was studied after $24 \mathrm{hrs}$ culture on three bacteria. The bacterial were Salmonella typhi, Escherichia coli and Klebsiella pneumonia which were obtained from stock cultures at virology Laboratory, Faculty of Resource and Technology Universiti Malaysia Sarawak.

With the aid of a single hole punch office paper perforator, circular discs of $5 \mathrm{~mm}$ diameter were cut from Whatman No 1 filter paper. The sensitivity of each test microorganism to the pure compounds was determined using the disc diffusion technique.

The growth inhibitory concentration of the pure compounds was significantly active on all the selected pathogen. From the result, greater antibacterial activity was shown against Salmonella typhi, Escherichia coli and Klebsielia pneumonia suggesting that the isolated compounds 2-Methyl biphenyl-4-Carboxylate (1) and Methyl salicylate (2) of Leptadenia hastata roots could be used as an agent for the treatment of causative and resistance bacteraemia infections.

Strong inhibition of 2-Methyl biphenyl-4-Carboxylate (1) was observed on Salmonella typhi at $100 \mathrm{ppm}$ of
$14.30 \pm 0.17 \mathrm{~mm}$, followed by Escherichia coli at the same concentration of $14.30 \pm 0.16 \mathrm{~mm}$. the lowest inhibition was observed at $25 \mathrm{ppm}$ of $0.89 \pm 0.14 \mathrm{~mm}$ when compared to the test control of $3.15 \pm 0.43 \mathrm{~mm}$ as shown in Table 12 .

Escherichia coli was observed to have higher inhibition by Methyl salicylate (2) at $100 \mathrm{ppm}$ of $14.80 \pm 0.19 \mathrm{~mm}$, there was a progressive inhibition with increase in concentration of the agent Methyl salicylate (2).

From the result obtained in Table.12, it was observed that the isolated compound Methyl biphenyl-4Carboxylate (1) shows weaker inhibition on Escherichia coli and Methyl salicylate (2) on Klebsielia pneumonia. However, there was a significant inhibition in all the concentrations as shown in Table 12.

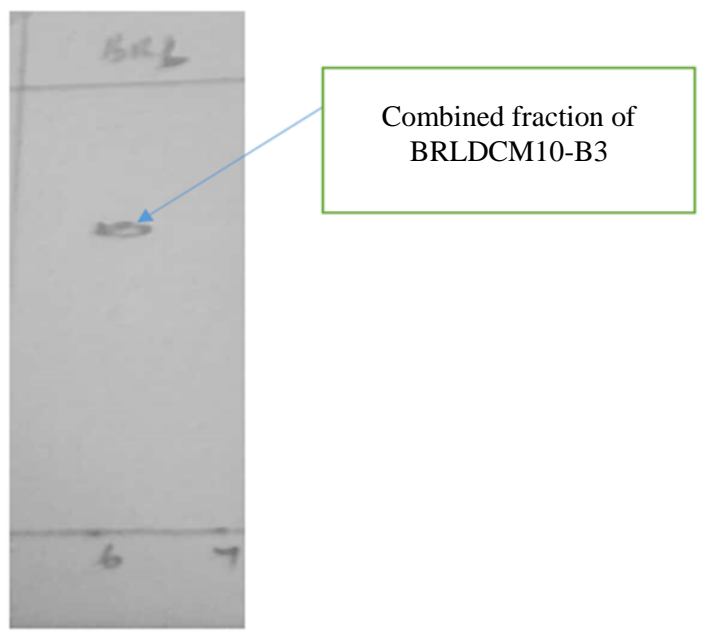

Fig. 10: TLC plate showing the spot of fraction LHRDCM10B2 in DCM: Chloroform

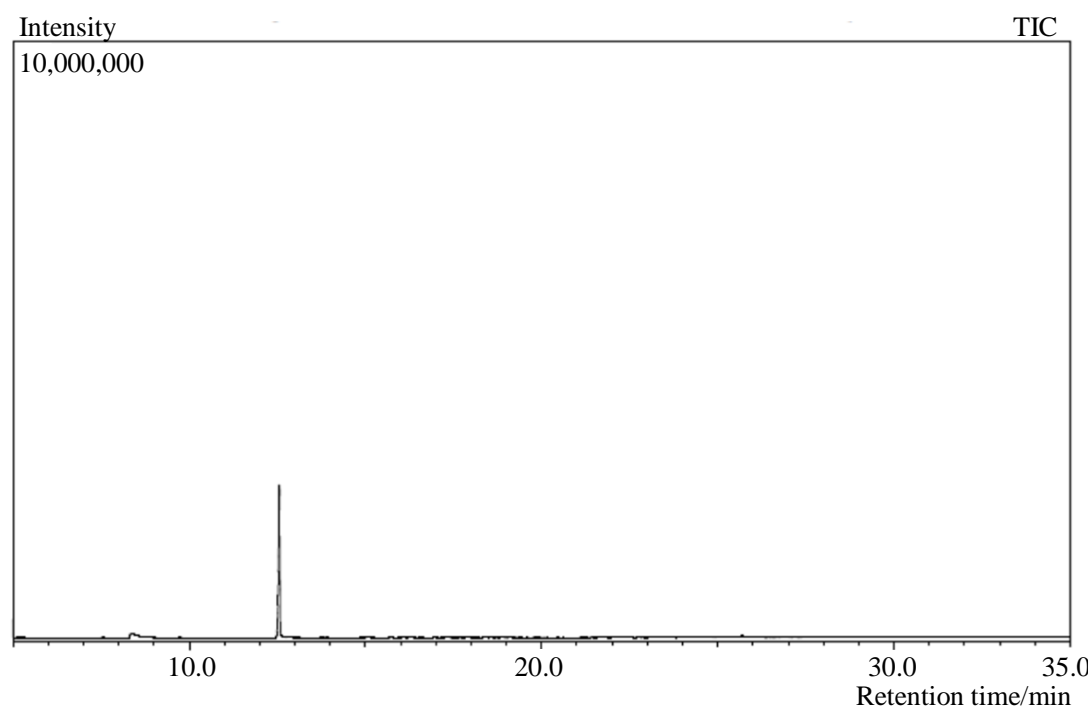

Fig. 11: Gas chromatogram of compound 2 
Isaac John Umaru and Hauwa A. Umaru / American Journal of Biochemistry and Bioztechnology 2019, 15 (4): 251.269 DOI: 10.3844/ajbbsp.2019.251.269

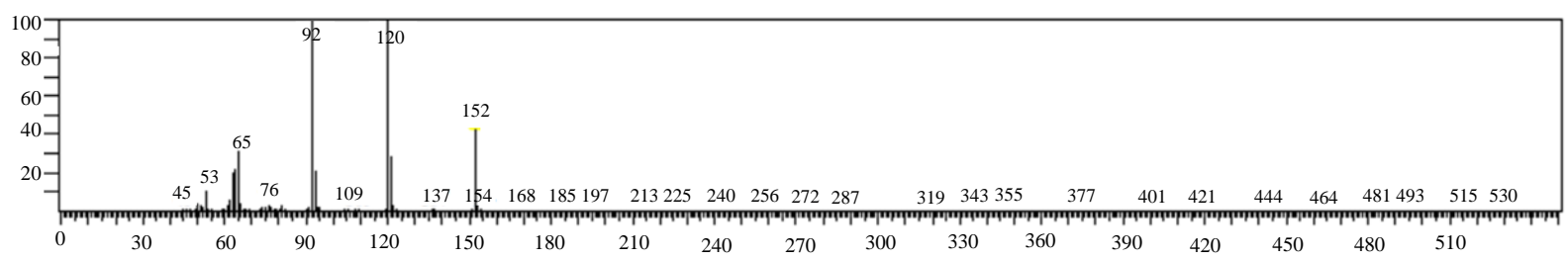

Fig. 12: Mass spectrum of compound 2

SI:96 Formula: C8H8O3 CAS:119-36-8 MolWeight: 152 RetIndex: 1281

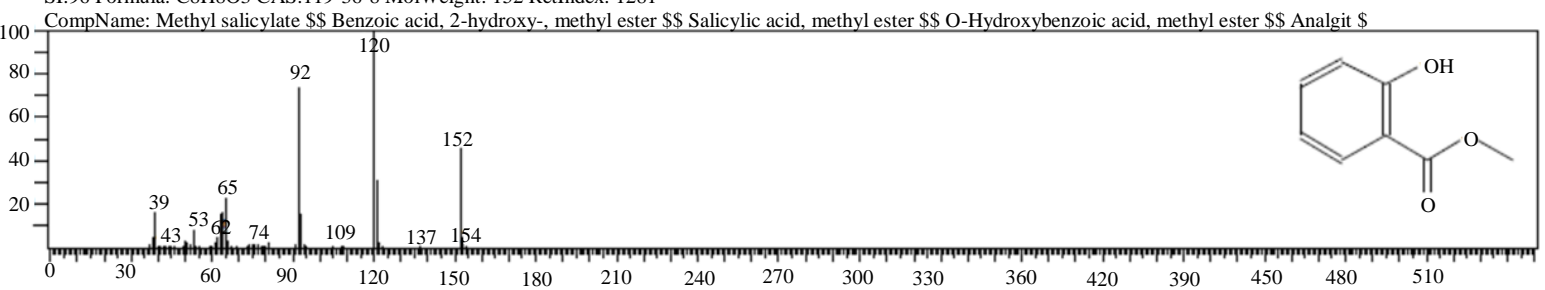

Fig. 13: Mass spectrum of suggested structure of compound 2 by NIST library

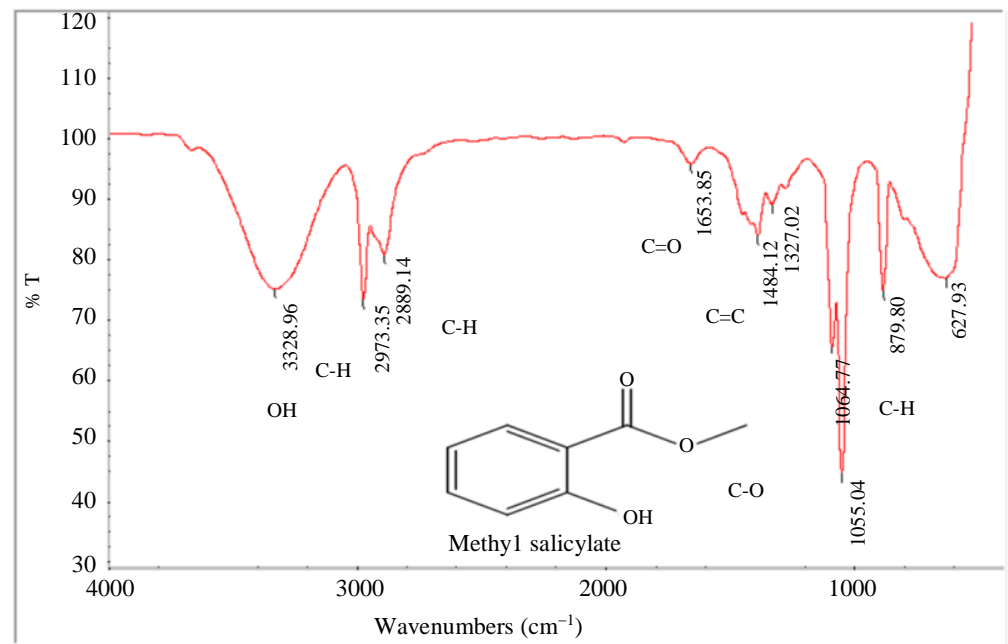

Fig. 14: IR spectrum of compound 2

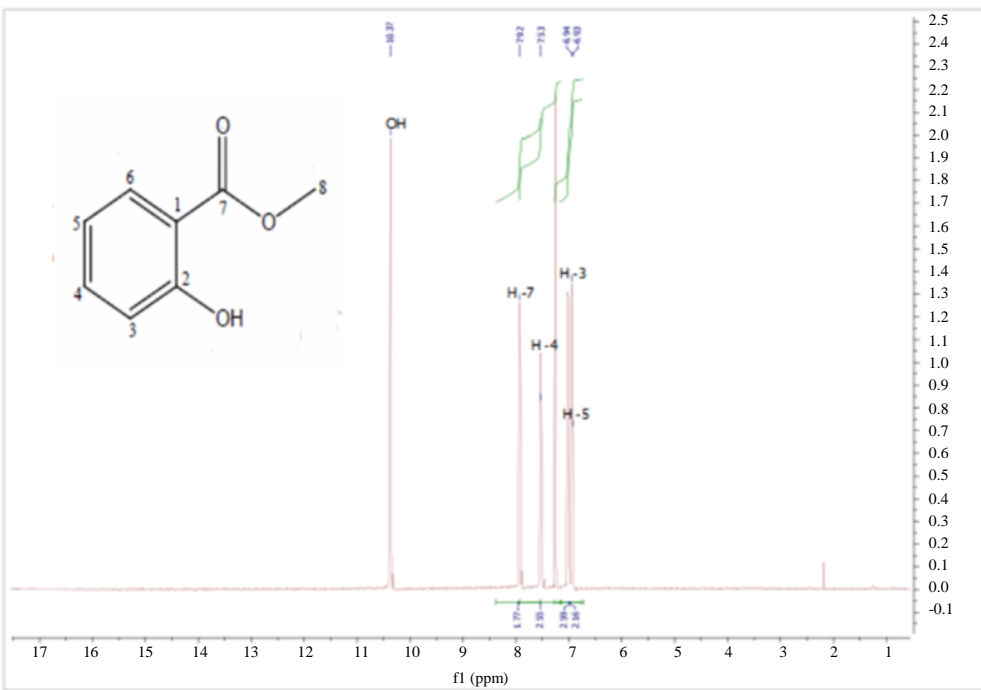

(a) 
Isaac John Umaru and Hauwa A. Umaru / American Journal of Biochemistry and Bioztechnology 2019, 15 (4): 251.269 DOI: 10.3844/ajbbsp.2019.251.269

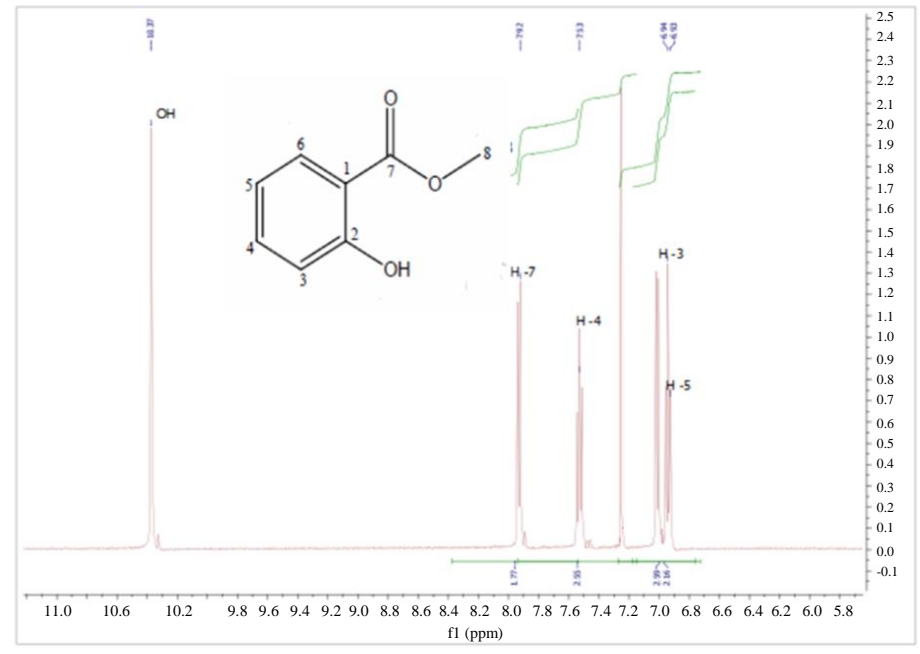

(b)

Fig. 15: (a) ${ }^{1} \mathrm{H}-\mathrm{NMR}$ spectrum of Compound 2 from 1 to $17\left(500 \mathrm{MHz}, \mathrm{CDCl}_{3}\right)$; (b) ${ }^{1} \mathrm{H}-\mathrm{NMR}$ spectrum of Compound 2 from 5.8 to $11.0\left(500 \mathrm{MHz}, \mathrm{CDCl}_{3}\right)$

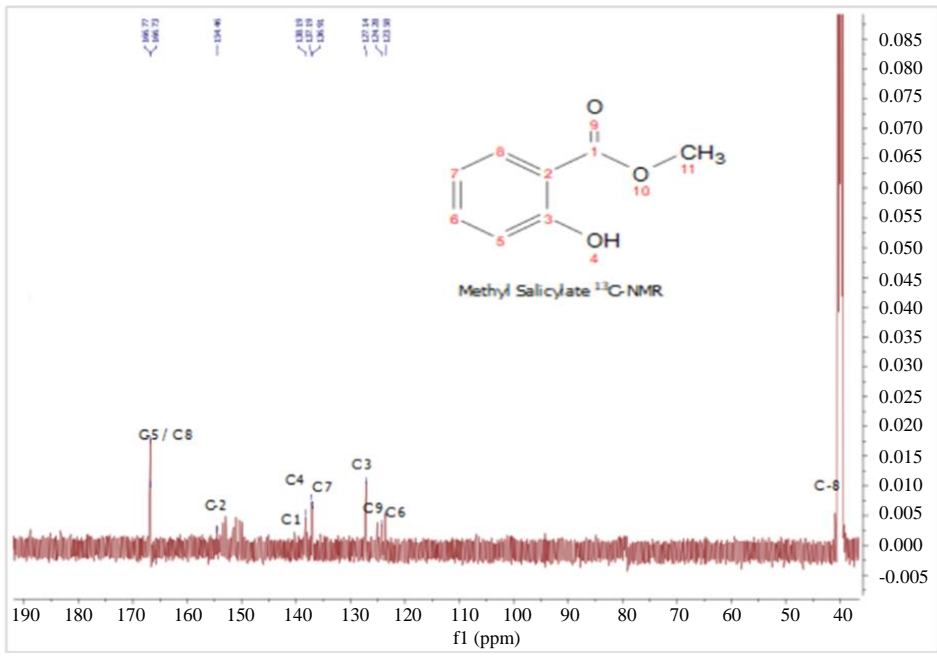

(a)

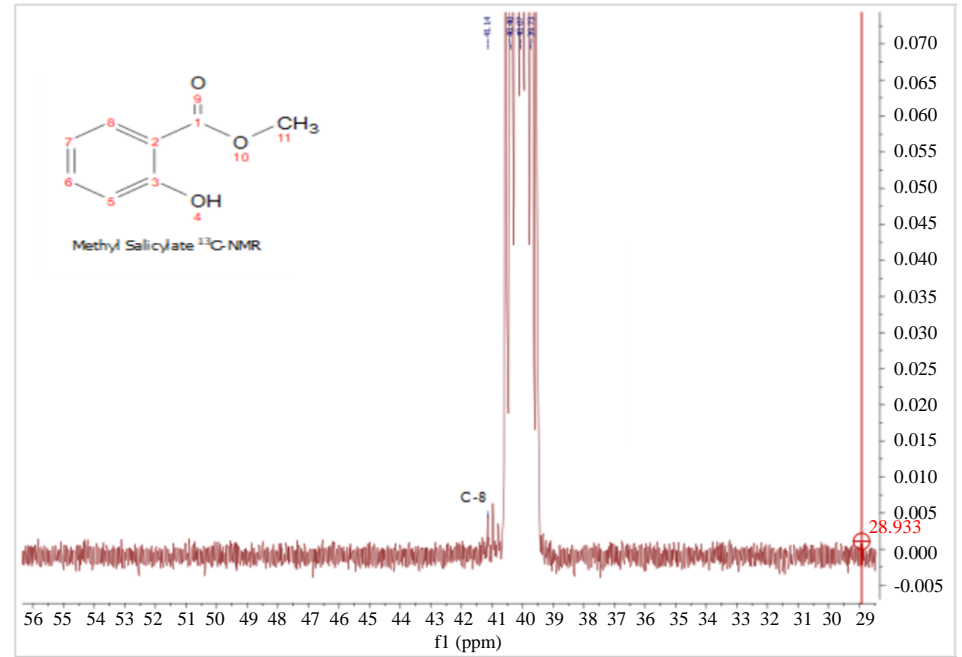

(b) 


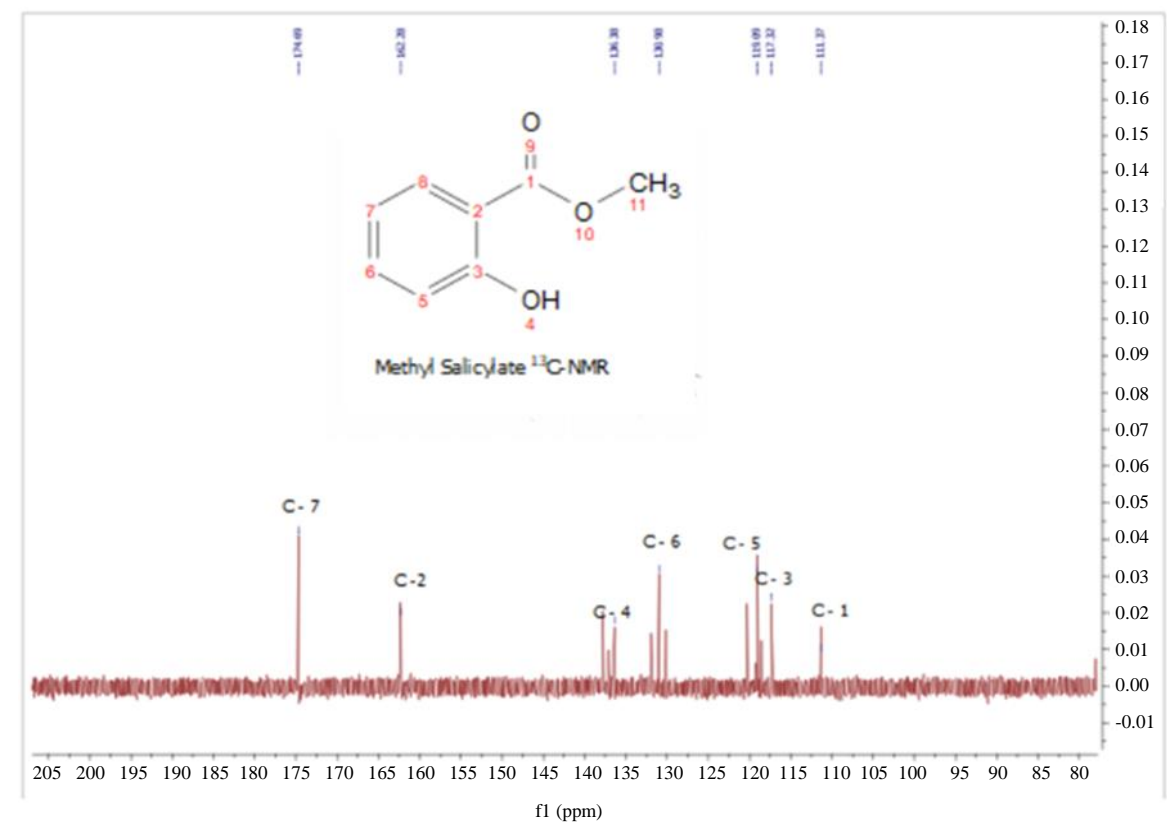

(c)

Fig. 16: (a) ${ }^{13} \mathrm{C}$-NMR spectrum of Compound 2 from 40 to 190 (125 MHz, $\mathrm{CDCl}_{3}$ ); (b) ${ }^{13} \mathrm{C}-\mathrm{NMR}$ spectrum of Compound 2 from 29 to $56\left(125 \mathrm{MHz}, \mathrm{CDCl}_{3}\right)$; (c) ${ }^{13} \mathrm{C}-\mathrm{NMR}$ spectrum of Compound 2 from 80 to $205\left(125 \mathrm{MHz}, \mathrm{CDCl}_{3}\right)$

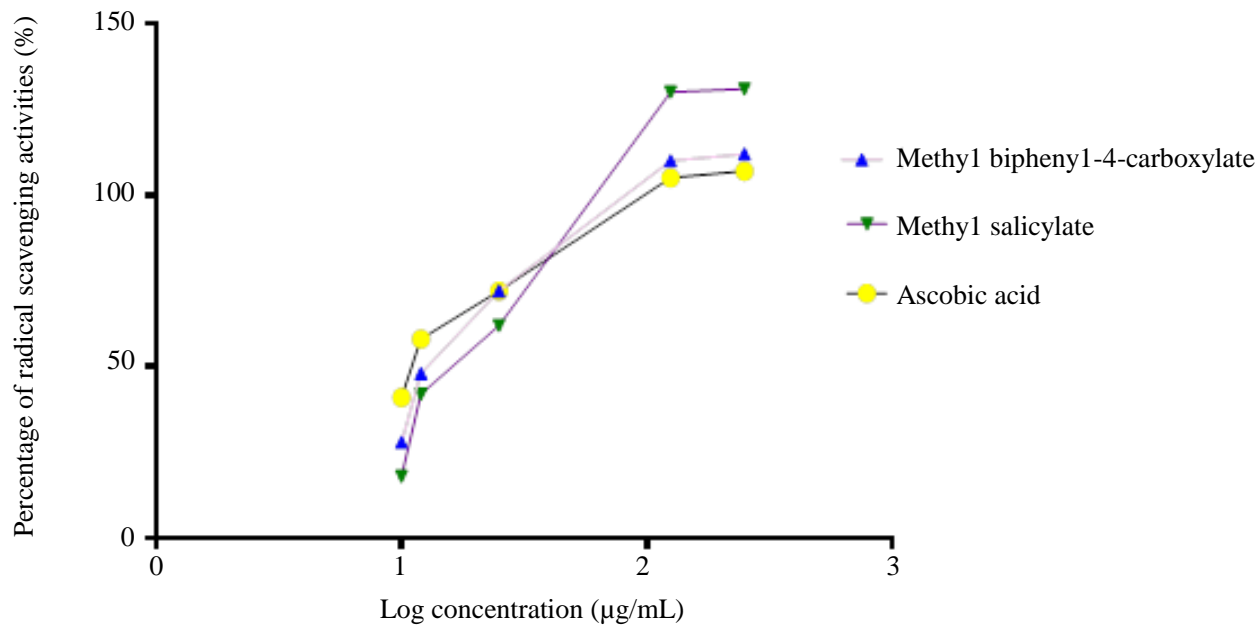

Fig. 17: Graph $\mathrm{IC}_{50}$ value of the isolated pure compound from Leptadenia hastata root extract

Table 12: Antibacterial activity of isolated pure compounds

\begin{tabular}{|c|c|c|c|c|c|}
\hline \multicolumn{6}{|l|}{ Concentration (ppm) } \\
\hline Isolated Compound & Organism & $\begin{array}{l}\text { Control(Tetracycline) } \\
(\mathrm{mm})\end{array}$ & $\begin{array}{l}25 \mathrm{ppm} \\
(\mathrm{mm})\end{array}$ & $\begin{array}{l}50 \mathrm{ppm} \\
(\mathrm{mm})\end{array}$ & $\begin{array}{l}100 \mathrm{ppm} \\
(\mathrm{mm})\end{array}$ \\
\hline & Escherichia coli & $18.30 \pm 1.6$ & $6.30 \pm 0.16$ & $8.30 \pm 0.16$ & $14.3 \pm 0.16 *$ \\
\hline 2-Methyl biphenyl-4- & Klebsiella pneumoniae & $20.80 \pm 2.2$ & $10.30 \pm 0.16$ & $11.0 \pm 0.28$ & $12.7 \pm 0.33$ \\
\hline \multirow[t]{2}{*}{ Carboxylate (1) } & Salmonella typhi & $26.1 \pm 3.40$ & $10.50 \pm 0.14$ & $4.50 \pm 0.14$ & $14.3 \pm 0.07$ \\
\hline & Escherichia coli & $18.30 \pm 1.6$ & $9.40 \pm 0.16$ & $11.30 \pm 0.16$ & $14.8 \pm 0.19 *$ \\
\hline \multirow[t]{2}{*}{ Methyl salicylate (2) } & Klebsiella pneumoniae & $20.80 \pm 2.2$ & $10.30 \pm 0.16$ & $11.1 \pm 0.05$ & $11.7 \pm 0.16$ \\
\hline & Salmonella typhi & $26.1 \pm 3.40$ & $12.30 \pm 0.16$ & $12.3 \pm 0.16$ & $13.3 \pm 0.15 *$ \\
\hline
\end{tabular}


Table 13: Antioxidant $\mathrm{IC}_{50}$ of pure compound isolated from Leptadenia hastata

\begin{tabular}{lll}
\hline Pure Compound & $\mathrm{IC}_{50}(\mu \mathrm{g} / \mathrm{mL})$ & $\mathrm{R}^{2}$ \\
\hline Methyl biphenyl-4-Carboxylate (1) & 66.51 & 0.9846 \\
Methyl salicylate (2) & 77.79 & 0.9552 \\
Ascorbic acid & 61.96 & 0.9767 \\
\hline
\end{tabular}

The isolated Compounds Methyl biphenyl-4Carboxylate (1), Methyl salicylate (2) have shown a very significant antioxidant activity as shown in Table 13. In this study, the absorbance was measured at $517 \mathrm{~nm}$. The data was statistically determined using Log dose inhibition curve in computerized PRISM programme, based on a percentage of DPPH scavenging of the chemical constituents Fig. 17 and Table 13. From the result it was observed that, the antioxidant potential $\left(\mathrm{IC}_{50}\right)$ of Methyl biphenyl-4-Carboxylate (1) and Methyl salicylate (2) showed significantly potential of 66.51 $\mu \mathrm{g} / \mathrm{mL}$ and $77.79 \mu \mathrm{g} / \mathrm{mL}$ respectively when compared to the standard $\mathrm{IC}_{50}$ of 61.96 as shown in Table 13.

\section{Conclusion}

The root extract of Leptadenia hastata showed an important pure compound which can be used as an agent to fight diseases and ailment that have become menace to the health management and disease control around the world. Physicochemical properties of the isolated compounds were as shown in Table 10. The pure compounds can as well be considered as a good source of natural antioxidant and antibacterial based on the study of the pure compounds activity. The potential of this compound with moderate cytotoxicity can work as an agents involving a free radicals quenching mechanism as well as inhibition of cancer development compounds. More studies related to these compounds Methyl biphenyl-4-Carboxylate (1) and Methyl salicylate (2) and other compounds can be considered using the flowchart Fig. 2 on the step by step isolation are recommended to update the efficacy in the field of health management and disease control.

\section{Acknowledgement}

The authors are grateful to Universiti Malaysia Sarawak for supporting this research. 07(ZRC05/1238/2015(2).

\section{Authors Contribution}

Isaac John Umaru: Conception and design, acquisition of data, analysis and interpretation of data.

Hauwa A. Umaru: Design, review and its intellectual content, final approval for submission.

\section{Supplementary Materials}

All supplementary materials regarding this work are available on request from the authors at Isaac.j62@yahoo.com

\section{Conflicts of Interest}

The authors declare that they have no conflicts of interest.

\section{Reference}

Asaduzzaman, M.D., M.D. Sohel-Rana, S.M. RaqibulHasan, M. Hossain and N. Das, 2015. Cytotoxic (brine shrimp lethality bioassay) and antioxidant investigation of Barringtonia acutangula (L.). Int. J. Pharm. Sci. Res., 6: 1179-1185.

Boyan, B., H. James and P. Judicael, 2005. Principles of accessing bacterial susceptibility to antibiotics using agar diffusion method. J. Antimicrobial. Chemotherapy, 61: 1295-1301.

DOI: 10.1093/jac/dkn090

Efdi, M., S. Fujita, T. Inuzuka and M. Koketsu, 2010. Chemical studies on Goniothalamus tapis Miq. Nat. Prod. Res., 24: 657-662. DOI: 10.1080/14786410903132449

Elumba, Z.S., F.G. Teves and M.R.S.B. Madamba, 2013. DNA-binding and cytotoxicity of supercritical- $\mathrm{CO}^{2}$ extracts of Ganoderma lucidum collected from the wild plant of Bukidnon province, Philippines. Int. Res. J. Biol. Sci., 2: 62-68.

Fasihuddin, B.A., N.K.N.M. Sallehuddin and Z. Assim, 2010. Chemical constituents and antiviral study of Goniothalamus velutinus. Malaysian J. Fundamental Applied Sci., 6: 73-76.

DOI: $10.11113 /$ mjfas. v6n1.180

Filho, V.C., O.G. Miguel, R.J. Nunes, J.B. Calixto and R.A. Yunes, 1995. Antispasmodic activity of xanthoxyline derivatives: Structure-activity relationships. J. Pharmaceut. Sci., 84: 473-475. DOI: $10.1002 /$ jps.2600840416

Firdous, A.M., A.L. Fayaz and A.S. Mushtaq, 2013. Isolation of active components derived from rhizome of Euphorbia wallichii Hook. Int. J. Ayurv Herb Med., 3: 1173-1183.

Hacksell, U., 1996. Structural and Physicochemical Factors in Drug Action. In: A Textbook of Drug Design and Development, Krogsgaard-Larsen, P., T. Liljefors and U. Madsen (Eds.), Harwood Academic Publishers, Amsterdam, ISBN-10: 3718658674, pp: 35-59.

Jadrijevic-Mladar, T.M. and T.D. Vikic, 2004. FT-IR and NMR spectroscopic studies of salicylic acid derivatives. II. Comparison of 2-hydroxy-and 2, 4and 2, 5-dihydroxy derivatives. Acta Pharmaceutica, 54: 177-191. 
Janice, G.S., 2008. Key Concepts-Mass Spectrometry, Infrared Spectroscopy and Nuclear Magnetic Resonance Spectroscopy. 2nd Ed., Organic Chemistry, New York, McGraw-Hill, pp: 485-525.

Kalaiselvan, A., K. Gokulakrishnan and T. Anand, 2012. Gas chromatography mass spectrum analysis of bioactive components of the ethanol extract of Andrographis paniculata. J. Pharmace. Biomed. Sci., 20: 1-3.

McLaughlin, J.L., L.L. Rogers and J.E. Anderson, 1998. The use of biological assays to evaluate botanicals. Drug Inform. J., 32: 513-524.

DOI: $10.1177 / 009286159803200223$

Meyer, B.N., N.R. Ferrigni, J.E. Putnam, L.B. Jacobsen and D.J. Nichols et al., 1982. Brine shrimp: A convenient general bioassay for active plant constituents. Planta Med., 45: 31-34.

DOI: $10.1055 / \mathrm{s}-2007-971236$

Mohanty, S.K., M.K. Swamy, U.R. Sinniah and M. Anuradha, 2017. Leptadenia reticulata (Retz.) Wight and Arn. (Jivanti): Botanical, agronomical, phytochemical, pharmacological and biotechnological aspects. Molecules, 22: 1019-1019. DOI: $10.3390 /$ molecules22061019

Moshi, M.J., E. Innocent, J.J. Magadula, D.F. Otieno and A. Weisheit et al., 2010. Brine shrimp toxicity of some plants used as traditional medicines in Kagera region, north western Tanzania. Tanzania J. Health Res., 12: 63-67. DOI: $10.4314 /$ thrb. v12i1.56287

Patil, S.P., P.D. Jain, J.S. Sancheti, P.J. Ghumatkar and R. Tambe et al., 2014. Neuroprotective and neurotrophic effects of apigenin and luteolin in MPTP induced parkinsonism in mice. Neuropharm, 86: 192-202.

DOI: 10.1016/j.neuropharm.2014.07.012

Patra, J.K., S. Gouda, S.K. Sahoo and H.N Thatoi, 2012. Chromatography separation, $1 \mathrm{H}$ NMR analysis and bioautography screening of methanol extract of Excoecaria agallocha L. from Bhitarkanika, Orissa, India. Asian Pacific J. Tropic Biomedi., 2: S50-S56.

DOI: 10.1016/S2221-1691(12)60129-4
Prashanth, V.K., N.S. Chauhan, H. Padh and M. Rajani, 2006. Search for antibacterial and antifungal agents from selected Indian medicinal plants. J. Ethno. Pharmacol., 107: 182-188. DOI: 10.1016/j.jep.2006.03.013

Sarah, Q.S., F.C. Anny and M. Misbahuddin, 2017. Rine shrimp lethality assay. Bangladesh J. Pharmacol.

Shalini, S. and P. Sampathkumar, 2012. Phytochemical screening and antimicrobial activity of plant extracts. Int. J. Current Sci., 20: 209-218.

Silverstein, R.M., F.X. Webster and D.J. Kiemle, 2005. Spectrometric Identification of Organic Compound. 7th Edn., John Wiley and Sons, ISBN-10: 0471429139.

Tailor, C.S. and A. Goyal, 2014. Antioxidant activity by DPPH radical scavenging method of Ageratum conyzoides Linn. leaves. Am. J. Ethnomedi., 1: 244-249.

Supplementary Materials, 2014. Supplementary materials 1. Characterization of palladium (II) complex. Molecule.

Thomas, S.D., 2012. Leptadenia hastata: A Review of its Traditional uses and its Pharmacol Activity. Med. Chem., 2: 144-150.

Umaru, I.J., F.A. Badruddin, Z.B, Assim and H.A Umaru, 2018. Antibacterial and cytotoxic actions of chloroform crude extract of Leptadenia hastata (Pers) decnee. Clinic Med. Biochem., 4: 1-4. DOI: 10.4172/2471-2663.1000139

Wang, H.X., C.M. Liu, Q. Liu and K. Gao, 2008. Three types of sesquiterpenes from rhizomes of Atractylodes lancea. Phytochemistry, 69: 2088-2094.

DOI: 10.1016/j.phytochem.2008.04.008 